archives-ouvertes

\title{
Researchers' perspectives on Industry 4.0: multi-disciplinary analysis and opportunities for operations management
}

Dmitry Ivanov, Christopher Tang, Alexandre Dolgui, Daria Battini, Ajay Das

\section{- To cite this version:}

Dmitry Ivanov, Christopher Tang, Alexandre Dolgui, Daria Battini, Ajay Das. Researchers' perspectives on Industry 4.0: multi-disciplinary analysis and opportunities for operations management. International Journal of Production Research, Taylor \& Francis, 2020, pp.1-24. 10.1080/00207543.2020.1798035 . hal-02923787

\section{HAL Id: hal-02923787 \\ https://hal.archives-ouvertes.fr/hal-02923787}

Submitted on 27 Aug 2020

HAL is a multi-disciplinary open access archive for the deposit and dissemination of scientific research documents, whether they are published or not. The documents may come from teaching and research institutions in France or abroad, or from public or private research centers.
L'archive ouverte pluridisciplinaire HAL, est destinée au dépôt et à la diffusion de documents scientifiques de niveau recherche, publiés ou non, émanant des établissements d'enseignement et de recherche français ou étrangers, des laboratoires publics ou privés. 


\title{
Researchers' Perspectives on Industry 4.0: Multi-Disciplinary Analysis and Opportunities for Operations Management
}

\author{
Dmitry Ivanov, Christopher S. Tang, Alexandre Dolgui, Daria Battini, Ajay Das
}

\author{
Dmitry Ivanov ${ }^{*}$, Christopher S. Tang ${ }^{2}$, Alexandre Dolgui ${ }^{3}$, Daria Battini ${ }^{4}$, Ajay Das $^{5}$ \\ ${ }^{1}$ Berlin School of Economics and Law \\ Supply Chain and Operations Management, 10825 Berlin, Germany \\ Phone: +49 30 85789155; E-Mail: divanov@hwr-berlin.de \\ ${ }^{2}$ University of California Los Angeles \\ Los Angeles, USA \\ E-Mail: chris.tang@anderson.ucla.edu \\ ${ }^{3}$ IMT Atlantique, LS2N - CNRS, La Chantrerie, 4 rue Alfred Kastler, 44307 Nantes, France \\ E-Mail: alexandre.dolgui@imt-atlantique.fr \\ ${ }^{4}$ Università degli Studi di Padova, Dipartimento di Tecnica e Gestione dei Sistemi Industriali, \\ Stradella San Nicola 3, 36100 Vicenza, Italy \\ E-mail: daria.battini@unipd.it \\ ${ }^{5}$ Narendra Paul Loomba Department of Management \\ Zicklin School of Business, CUNY-Baruch \\ One Bernard Baruch Way \\ New York, NY 10010, USA \\ ajay.das@baruch.cuny.edu
}

\begin{abstract}
While Industry 4.0 has been trending in practice and research, operations management studies in this area remain nascent. Our intent is to understand the current state of research in Industry 4.0 in different disciplines and deduce insights and opportunities for future research in operations management. In this paper, we provide a focused analysis to examine the state-of-the-art research in Industry 4.0. To learn about researchers' perspectives about Industry 4.0, we conducted a large-scale, cross-disciplinary and global survey on Industry 4.0 topics among researchers in industrial engineering, operations management, operations research, control and data science at the $9^{\text {th }}$ IFAC MIM 2019 Conference in Berlin in August 2019. By using our survey findings and literature analysis, we build structural and conceptual frameworks to understand the current state of knowledge and to propose future research opportunities for operations management scholars.
\end{abstract}

Keywords: Industry 4.0, operations management, industrial engineering, data science, operations research, control, framework

\section{Glossary of Abbreviations:}

\begin{tabular}{|l|l|}
\hline AGV & Automated guided vehicle \\
\hline AI & Artificial intelligence \\
\hline APS & $\begin{array}{l}\text { Advanced planning system: a wide variety of software tools and techniques, with many applications } \\
\text { in manufacturing and logistics (including the service sector). }\end{array}$ \\
\hline BDA & Big data analytics \\
\hline CAS & $\begin{array}{l}\text { Complex adaptive system: a system composed of many interacting parts that evolve and adapt over } \\
\text { time }\end{array}$ \\
\hline CIM & Computer integrated manufacturing \\
\hline
\end{tabular}




\begin{tabular}{|l|l|}
\hline CPFR & Collaborative planning, forecasting and replenishment \\
\hline CPS & Cyber-physical system: a seamless integration of computation and physical components. \\
\hline DAMCLS & Decision analysis, modelling, control and learning systems \\
\hline ERP & Enterprise resource planning \\
\hline FMS & Flexible manufacturing system \\
\hline I4.0 & Industry 4.0 \\
\hline IFAC & $\begin{array}{l}\text { International Federation of Automatic Control: a federation is concerned with the impact of control } \\
\text { technology on society }\end{array}$ \\
\hline IME & Industrial and mechanical engineering \\
\hline IoT & Internet-of-Things \\
\hline IT & Information technology \\
\hline M2M & Machine-to-machine \\
\hline MAS & $\begin{array}{l}\text { Multi-agent system: a loosely coupled network of software agents that interact to solve problems } \\
\text { that are beyond the individual capacities or knowledge of each problem solver. }\end{array}$ \\
\hline OR & Operations research \\
\hline RFID & $\begin{array}{l}\text { Radio frequency identification: a technology that uses electromagnetic fields to automatically iden- } \\
\text { tify and track tags attached to objects. }\end{array}$ \\
\hline RMS & $\begin{array}{l}\text { Reconfigurable manufacturing system: a manufacturing system that can change and evolve rapidly } \\
\text { in order to adjust its productivity capacity and functionality. }\end{array}$ \\
\hline OM & Operations management \\
\hline T\&T & Track and trace system \\
\hline VCA & VOSviewer co-occurrence analysis: a software tool for visualizing bibliometric networks \\
\hline VMI & Vendor-managed inventory \\
\hline
\end{tabular}




\section{Introduction}

Industry 4.0 has become a popular term for characterizing the ongoing transformations of manufacturing and supply chain networks. However, its definition depends on the context. Consider Audi and Siemens as examples of these technology-driven transformations. First, consider the Audi's smart factory in BadenWürttemberg. Unlike traditional assembly systems with fixed layouts and process designs, this smart factory leverages highly flexible process design and sequencing of production orders to achieve a high degree of customization while remaining efficient (Audi 2019). Second, by using an open operating system and Internet-of-Things (IoT), Siemens' cloud-based manufacturing platform MindSphere can generate information for advance analytics to digitally manage different interconnected systems and machines in different factories (Siemens 2018).

Besides practitioners, the definition of I4.0 varies across academic disciplines. In disciplines such as engineering, management, control, and data science, I4.0 has been characterized as technological advances, organizational re-designs, operations management (OM) developments, and market transformations (Yin et al. 2018, Tang and Veelenturf 2019, Oztemel and Gursev 2020). For example, in the management area, Piccarosi et al. (2018) state that "Industry 4.0 refers to the integration of Internet of Things technologies into industrial value creation enabling manufacturers to harness entirely digitized, connected, smart, and decentralized value chains able to deliver greater flexibility and robustness to firm competitiveness and enable them to build flexible and adaptable business structures [acquiring] the permanent ability for internal evolutionary developments in order to cope with a changing business environment as the result of a purposely formulated strategy implemented over time". Oztemel and Gursev (2020) define I4.0 as "A methodology to generate a transformation from machine dominant manufacturing to digital manufacturing". These varying definition of I4.0 reveal that research on I4.0 has been fragmented and disciplinespecific (Ivanov et al. 2016, Liao et al. 2017, Panetto et al. 2019).

In the OM research discipline, there are few studies focusing on I4.0. Recent works (Ivanov et al. 2019, Tang and Veelenturf, 2019, Olsen and Tomlin, 2020; Calzavara et al., 2020) showed that, within the I4.0 context, OM research has been predominantly focusing on the manufacturing applications of the technologies such as additive manufacturing, Internet of Things, blockchain, advanced robotics, and artificial intelligence. While some research casts I4.0 as a revolution (i.e., the 4th industrial revolution), more granular views envisage I4.0 as an integrity of technologies and management-organizational principles in manufacturing and supply chains in the first decades of the XXI century (Mittal et al. 2018, Xu et al. 2018, Frank et al. 2019). In this paper, we focus on the latter. Due to a lack of consistent definition, we shall define I4.0 from the OM perspective as follows:

Industry 4.0 is an integrity of technologies, organizational concepts and management principles underlying a cost-efficient, responsive, resilient and sustainable network, data-driven and dynamically and structurally adaptable to changes in the demand and supply environment through rapid rearrangement and reallocation of its components and capabilities.

Although our definition of I4.0 entails technology and management, the theoretical underpinning and framing of the integration of technology and management is at its infancy. Specifically, the current literature on I4.0 does not integrate or synthesize disciplinary sensitivities; instead, it remains diversely separated by engineering, management, control, and data science perspectives. Further research into framing I4.0 perspective in OM through a multi-disciplinary lens appears to be necessary and important.

These observations motivate us to examine the current state of research in I4.0 in different disciplines and deduce insights and opportunities for future research in OM. Specifically, our intent is to examine the following questions:

\section{1) What is state of the art in research in I4.0 in different disciplines?}

2) What are the differences and consistencies in focus and perspective in research on I4.0 across different disciplines (engineering, OM, control, and data science)? 


\section{3) What are the topics and research opportunities for OM in I4.0?}

To examine these questions, we utilize the explanatory study methodology along with the literature analysis. Our approach is similar to the approach presented in Sodhi et al. (2012) and Schoenherr and SpeierPero (2015). Specifically, we rely on two data sources to develop our insights. First, we conduct a bibliometric analysis of the literature reviews and surveys on I4.0 in order to understand the current state of the art in OM research in I4.0. We identify and group major knowledge clusters and their contents. Second, associated with the $9^{\text {th }}$ IFAC $^{1}$ Conference on Manufacturing Modeling, Management and Control (MIM 2019) of August 28-30, 2019, we conducted a large-scale, cross-disciplinary and global survey on I4.0 topics among researchers in industrial engineering, OM, operations research, control and data science. By using our literature analysis and our survey data, we propose some OM research opportunities in I4.0.

The rest of the paper is organized as follows. Section 2 selectively examines I4.0-related literature, including both surveys and primary research ${ }^{2}$. Section 3 describes and discusses the results of our survey on multidisciplinary researchers' perspectives on I4.0. Section 4 deliberates on the specifics of multi-disciplinary collaboration, and points to emerging research opportunities. Section 5 concludes the study with a summary of the main results.

\section{State of the art research in $\mathbf{I} 4.0$}

We engaged in a concentric search, beginning with I4.0 papers in general, and narrowed it down to OM related research studies. We conducted a systematic bibliometric co-occurrence analysis in the SCOPUS database (on September 24, 2019) and a subsequent co-occurrence analysis of the literature reviews on I4.0 employing the VOSviewer Co-occurrence Analysis (VCA; www.vosviewer.com) (van Eck and Waltman, 2009).

\subsection{Literature Search for Studies in I4.0}

We conducted a SCOPUS search by using the keywords "Industry4.0" AND "Literature review" OR "survey" and generated 692 results; restricting to articles and journals yielded 308 results; restricting to "Business and Management", "Engineering", "Decision Sciences" and "Computer Sciences" yielded 191 results. A VOSviewer Citation Co-Occurrence analysis was performed on those 191 studies, leading 80 common keywords with a minimum occurrence of 4 . The result after excluding non-relevant keywords ("surveys", "literature review") is shown in Figure1.

Figure 1 displays different "clusters" of the most common keywords in the papers related to Industry 4.0. Analysis of the keywords in each of the clusters identified and shown in Figure 1 in different colors allows for some observations regarding the I4.0 topics in literature. From Figure 1, we observe three distinctive "major research streams" in the context of I4.0 research that can be described as follows:

1. Management stream (red color): supply chain / operations management and operations research (e.g., lean management, supply chain management, planning, scheduling, and maintenance).

2. Organizational stream (blue color), (e.g., cloud manufacturing, digital supply chain, sustainability and innovation)

3. Technological stream (purple, green and yellow colors): data science topics (e.g., Internet-ofThings, artificial intelligence, learning systems and data handling), industrial and mechanical engineering topics (e.g., automation, additive manufacturing, production control and manufacturing processes), and control topics (e.g., cyber-physical systems, embedded systems and flow control).

\footnotetext{
${ }^{1} 9^{\text {th }}$ IFAC (International Federation of Automatic Control) Conference on Manufacturing Modelling, Management and Control (MIM 2019) held in Berlin on August 28-30, 2019

${ }^{2}$ As a disclaimer, this paper is not intended to be a comprehensive review of I4.0 literature.
} 


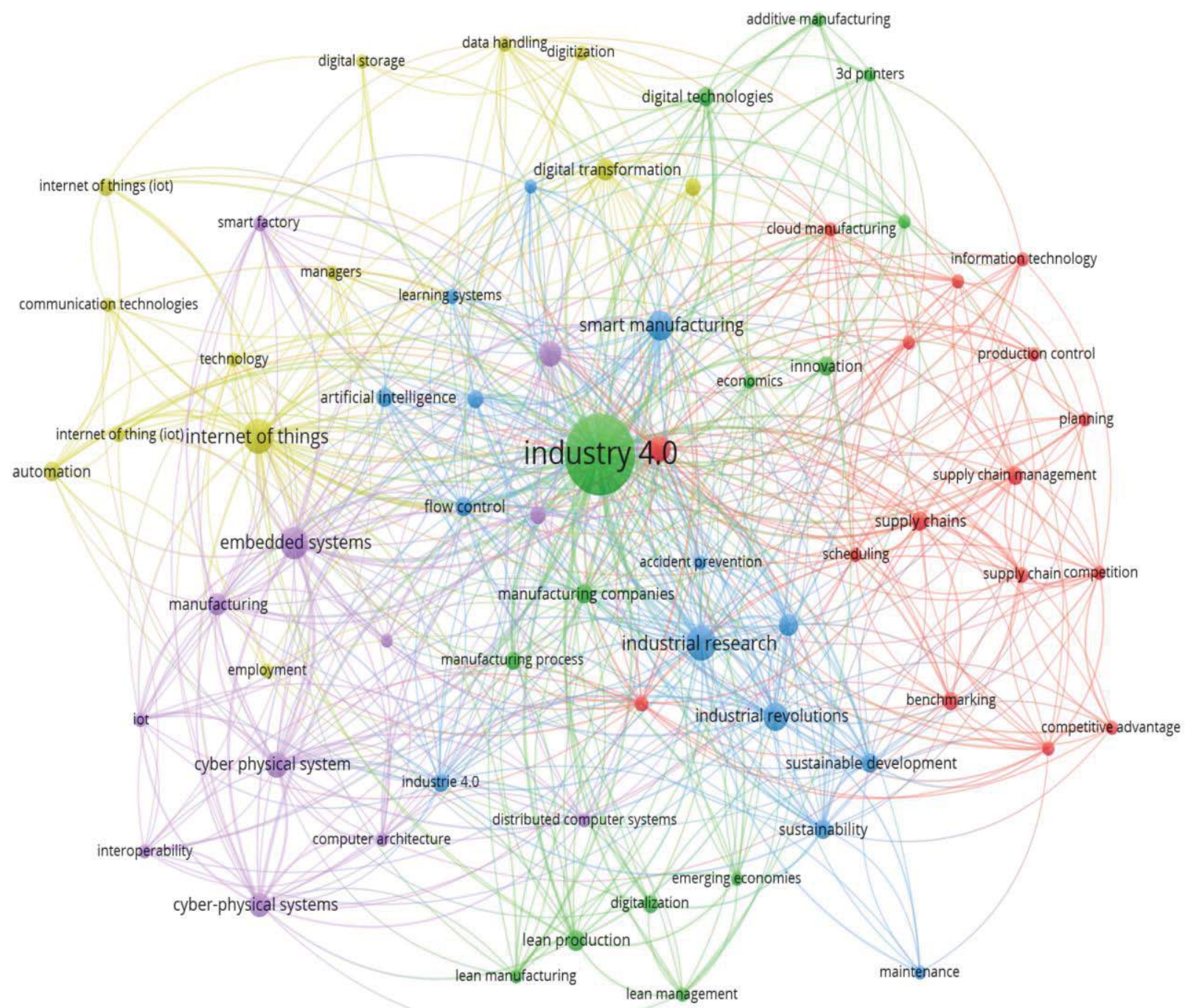

Figure 1. Bibliographic co-occurrence data map.

To distill our literature analysis further, we restricted ourselves to 49 articles which contain both surveys (19 articles) and primary research of I4.0 (36 articles). The selection of primary research papers was based on the framing of different I4.0 perspectives and tools (i.e., data science, engineering, control) in the OM context. $^{3}$

The management stream is comprised of 4 surveys, and 17 primary research articles. Dubey et al. (2019a), Ivanov et al. (2019) and Ivanov and Dolgui (2020) pointed out several intersections of Industry 4.0 and SC risk management. Tang and Veelenturf (2019) focused on the logistics issues in the I4.0 era and identified additive manufacturing, advanced robotics, artificial intelligence, autonomous vehicles, blockchain, drones, Internet-of-Things (IoT) as major technologies to implement I4.0. Some applications of operations research, industrial engineering and control methodologies to OM problems in the I4.0 context have been shown for shop floor control (Zhong et al. 2017, Yang et al. 2019), scheduling (Ivanov et al. 2016, 2018, Dolgui et al. 2019, Rossit et al. 2019), production line design by using mobile robots (Fragapane et al. 2020), smart contract design by blockchain (Dolgui et al. 2020), and supply chain resilience (Ivanov et al. 2019, Ivanov and Dolgui 2020). Yin et al. (2018) and Buer et al. (2018) offer insights on the formation of I4.0 through the evolution from flexible and reconfigurable manufacturing systems and lean manufacturing towards production environments build by a composition of IoT, big data, electric vehicles, 3D printing, cloud computing, artificial intelligence, and cyber-physical systems. Johnson et al. (2016) analyzed the application of data analytics in retail to improve revenue management. The studies by Oesterreich and

\footnotetext{
${ }^{3}$ Pure technological papers showing advances in some technologies without any relations to OM have been excluded from the analysis.
} 
Teuteberg (2016), Nayak et al. (2016), Moghaddam and Nof (2017) provide evidence of demand and manufacturing flexibility increases, product diversification, higher market responsiveness, shorter lead times and better capacity utilizations using Industry 4.0 technology.

The organizational stream includes 3 surveys, and 8 primary research articles. Mittal et al. (2018) underline the role of leadership and operational capabilities required for I4.0 adoption. They develop a maturity model of transition to I4.0 connecting production and logistics management processes with IoT and engineering infrastructures. Panetto et al. (2019) develop a cyber-physical perspective of I4.0, including the plant level, supply chain level, and networking levels in the analysis. They call for new business models utilizing potential I4.0 advantages in terms of flexibility, open systems and dynamic control. Raj et al. (2020) perform a cross-country analysis of barriers for I4.0 adoption. High investment in I4.0 implementation, lack of clarity regarding economic benefit, challenges in value-chain integration, lack of infrastructure and lack of digital skills and digital culture have been identified as critical problems for I4.0 adoption. These results are echoed by Frank et al. (2019). Jaboour et al. (2018) examine sustainability issues arising from I4.0, which can have both positive and negative environmental and society impacts. Organisational implications of some elements of I4.0, for e.g., big data analytics, have been addressed in studies by Wamba et al. (2017) and Dubey et al. (2019a, b). Ivanov et al. (2019) and Ivanov and Dolgui (2020) conceptualize the notions of digital supply chains and digital twins that organize supply chains and operations as cyber-physical enterprises that perform dynamic allocations of processes and dynamic supply chain structures.

The technological stream appears to reside in the disciplines of "Data science", "Mechanical and industrial engineering" and "Control". This stream of research is rather technical and focuses on the technological developments in I4.0. We decided to focus on 3 articles (i.e., Alcácer and Cruz-Machado (2019); Oztemel and Gursev (2020); and Xu et al. (2018)) because these articles appeared to be the most depictive and representative for the purposes of our study, and represent the state-of-the-art in the technological research clusters (i.e., they specifically focus on the technological aspects of I4.0) as shown in Table 1. 


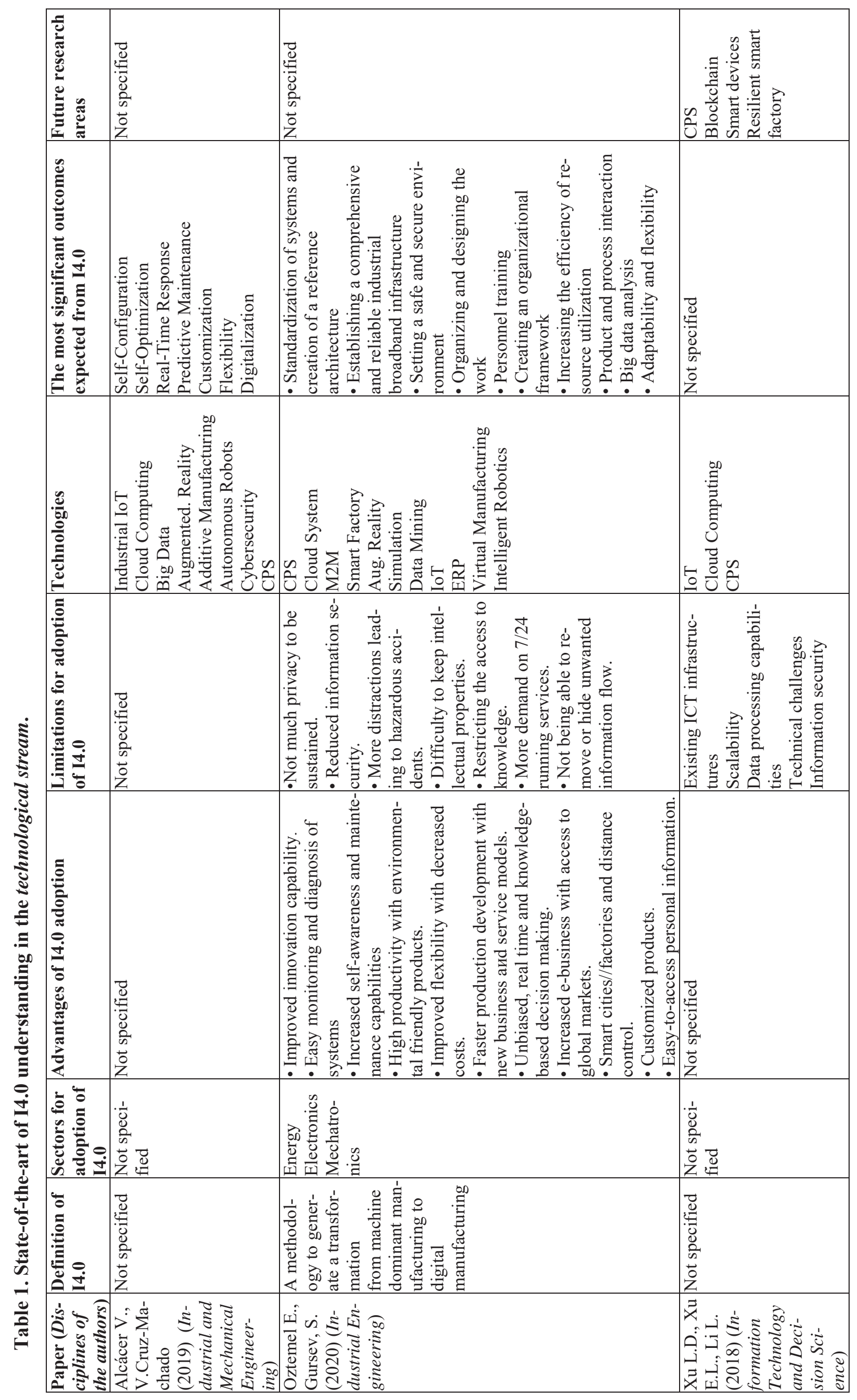




\subsection{Chronological Development of Industry 4.0 from OM Perspective}

The above literature analysis offers two observations. First, the potential benefits of I4.0 are directly related to OM. To elaborate, observe from Table 1 that the perceived advantages and expected outcomes of using various I4.0 technologies are standard OM performance measures including higher productivity, improved flexibility, and shorter times-to-market. Second, besides fragmented studies of I4.0 conducted by researchers in different disciplines as depicted in Figure 1, OM research studies of 4.0 are virtually non-existent. These two observations motivate us to develop a framework of I4.0 formation across different disciplines in the OM context as shown in Figure 2.
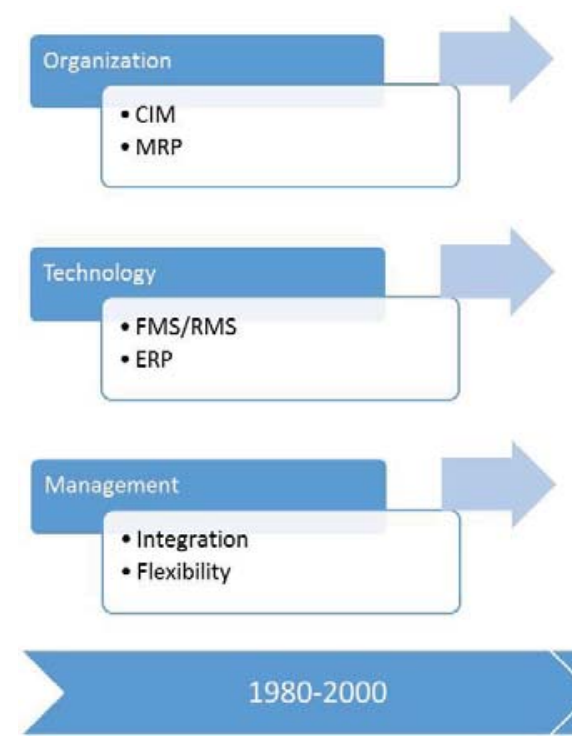

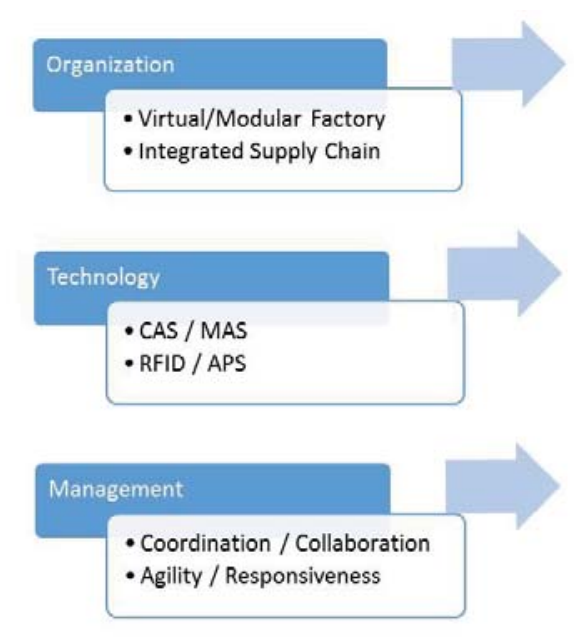

2000-2015

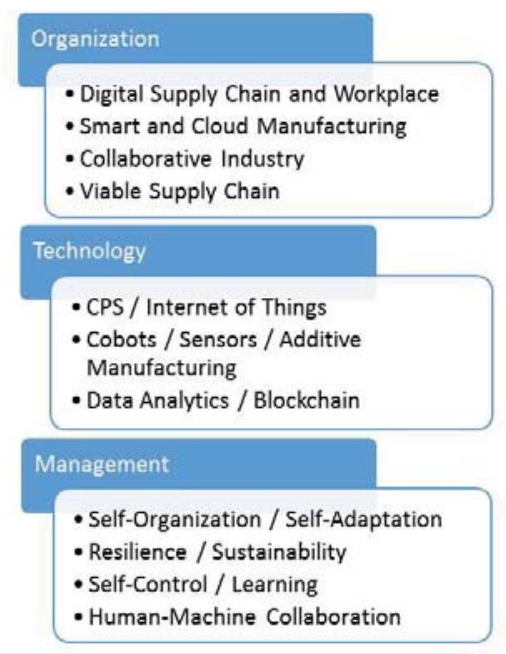

2015-2030

Figure 2. A 3D-Framework of I4.0 formation

The development of Figure 2 can be explained as follows. First, recall from Figure 1 that we have identified 3 research clusters (organization, technology, and management) from our literature analysis. Second, we treat each cluster as a "dimension" and some of the nodes associated with each cluster in Figure 1 as "elements" of each dimension. (A glossary of abbreviation is provided at the beginning of this paper.) Third, we organize these elements associated with each cluster and then present how these elements evolved over time by using a 3-dimension (3D) framework as shown in Figure 2. Our 3D-framework is built upon an integrity of management, physical and technological systems (Amaral and Uzzi, 2007). By reviewing Figures 1 and 2 and Table 1, we examine the current state of research, and answer our first question: "What is the State of Art in I4.0 in different disciplines?"

Buer et al. (2017), Liao et al. (2017), Kusiak et al. (2018), Yin et al. (2018), Frank et al. (2019), Tang and Veelenturf (2019) offer insightful overviews of the developments in organization, technology and management over the last four decades that culminated in I4.0. Looking back, the 1980-1990s witnessed a transformation from stable markets served with mass production, to increasingly volatile variety and volume market environments that required adaptable, small lot manufacturing using technologies such as flexible manufacturing systems (FMS) and reconfigurable manufacturing systems (RMS) (Stecke 1983, Slack 1987, Bordoloi et al. 1999, Koren et al. 1999, Dsouza and Williams 2000). At the same time, production and information technology advances lead to the establishment of computer-integrated manufacturing (CIM) and automated manufacturing processes, enabled and supported by novel systems such as enterprise resource planning (ERP) and modular and fractal factories (Tully 1993, Warnecke and Braun 1999, Wiendahl et al. 2015). Flexibility and integration became the key management and organizational principles of these times (Jordan and Graves 1995, Das et al. 2006).

The evolution between 2000 and 2010 was characterized by the development of such management principles as coordination, collaboration, decentralization and agility (Nof et al. 2006, Gunasekaran and Ngai 2009, Dekkers 2009, Chou et al 2010) to serve the increasingly volatile new market models (Kumar et al. 
2018, Demirezen et al. 2019). The implementation of these new organizational principles became possible due to advances in information and manufacturing technology such as multi-agent systems (Swaminathan et al. 1998, Fox et al. 2000), complex adaptive systems (Choi et al. 2001, Surana et a. 2005, Pathak et al. 2007, Nair and Vidal 2011), RFID (Lin and Visih 2006, Lee and Özer 2007, Wamba and Chatfield 2009), and APS (advanced planning systems) (Stadler et al. 2012). Vendor-managed inventory (VMI) and collaborative planning, forecasting and replenishment (CPFR) concepts as well as the virtual enterprise framework (Fry et al. 2001, Disney and Towill 2003, Sari 2008, Camarinha-Matos 2009, Ivanov and Sokolov 2010, Yao et al. 2013) were developed around the same period of time. Supply chain dynamics in virtual enterprises featured so-called competence cells or agents networking (Ivanov and Sokolov 2012). Another contribution, collaborative control theory, can be considered as one of the milestones in the development of manufacturing enterprise systems (Nof 2007). The central idea of collaborative control is to combine decentralized agent-oriented control in the framework of bio-inspired coordination and control, adaptation, and learning.

The beginnings of the 2010s saw a certain degree of industry familiarity with the individual components of a nascent I4.0 (e.g., collaborative robots (cobots), sensors, agents, modular factories, Internet-of-Things (IoT), etc.), but their relative utility and usage contexts and requirements were not clear (Zühlke et al 2009). In addition, attempts to interconnect these local solutions usually failed. This became possible later, following the rapid progress in data processing and robotics technologies (Meyer et al. 2014, Johnson et al. 2016, Choi et al. 2018, Mittal et al. 2018, Yin et al. 2018, Yu et al. 2018, Alcacer and Cruz-Machado 2019, Ben-Daya et al. 2019, Tang and Veelenturf 2019, Calzavara et al, 2020). Digital supply chain, smart manufacturing and cloud manufacturing are becoming important outcomes of I4.0 (Ivanov et al. 2018, Kusiak 2018, Liu et al. 2019, Rossit et al. 2019, Tao et al. 2019, Yang et al. 2019, Xu et al. 2019, Ivanov and Dolgui 2020, Ivanov et al. 2020). Sensors, automated guided vehicles (AGV), blockchain, additive manufacturing, augmented reality, big data analytics, track\&trace systems (T\&T), and mobile robots are facilitating the formation of cyber-physical systems (CPS) in manufacturing and supply chains (Waller and Fawcett 2013, Li et al. 2017, Wamba et al. 2017, Ivanov et al. 2018, Moghaddam and Nof 2018, Dubey et al. 2019a,b, Fragapane et al. 2020, Ivanov et al. 2019, Panetto et al. 2019, Dolgui et al. 2020, Ivanov and Dolgui 2020).

As a consequence, new disruptive manufacturing and supply chain business models arose where supply chains are no more regarded as rigid physical systems with fixed and static allocation of specific processes to specific firms. Instead, different physical enterprises offer services in supply, manufacturing, logistics, and sales at different times, resulting in the dynamic allocation of processes and dynamic supply chain structures. For example, electronic retailers are using their extensive transactional and behavioural customer data to offer customers new ways of trying, experiencing, and purchasing their products (e.g., Amazon with Alexa). Examples of digitalized supply chain and operations include logistics and supply chain control with real-time data (Park et al. 2018), dynamic resource allocation in I4.0 customised assembly systems (Ivanov et al. 2016), improving forecasting models using Big Data (Johnson et al. 2016), combining optimisation, machine learning algorithms and agent-based modelling for supply chain resilience (Cavalcantea et al. 2019, Ivanov 2018, Zhao et al. 2019).

I4.0 borrows several principles from systems, information, organization and network theories. The Beer's viable system model (Beer 1985) describes how interconnected operations communicate with changing market environments and meta-systems such as markets, policy, and society. Ashby's law of requisite variety (Ashby, 1956) prescribes that situational variety should be balanced by the response variety of the controller or "only variety absorbs variety". Viewed through the Ashby (1956) theoretical lens, I4.0 represents highly diversified and decentralized design and delivery systems able to respond to the increasing variety in external systems such as new market models (e.g., omnichannel), new business models (e.g., circular economy) positive disruptions (e.g., innovations) and negative disruptions (e.g., natural catastrophes) (Sodhi and Tang 2012, Papadopoulos et al. 2017, Zhong et al. 2017, Ivanov 2018, Jabbour et al. 2018, Aldrighetti et al, 2019, Luthra et al. 2020, Machado et al. 2020). Another series of studies (Casti (1979), Barabasi (2005), Ivanov and Sokolov (2010), Basole and Bellamy (2014) offer insights into the structural dynamics of the networks, their connectivity, feedbacks, visibility, coordination, (self)-adaptation and (self)-learning, following the fundamentals (Maruyama 1963, Bellmann 1972, Mesarovic and Takahara 
1975, Beer 1985). Moreover, I4.0 poses open system context analysis. An open system (Mesarovic and Takahara 1975, Casti et al. 1979) is a system that has interactions with the environments, and evolves based on these interactions. The major characteristics of open systems are control, self-adaptation, and self-organization (von Bertallanfy 1969, Anderson 1999, Gao et al. 2016) which can be seen as future-leading management principles in the era of I4.0. In addition, Industry 4.0 can contribute to supply chain viability at a larger scale (Ivanov and Dolgui 2020b, Ivanov 2020).

In summary, our response to the first question "What is state-of-the-art in I4.0 in different disciplines?" can be described as follows. It can be observed from the literature in the management stream that production planning and control, inventory management, process design, and scheduling dominate the applications of I4.0 to OM across the management decision-making areas. Strategic areas such as production, sourcing and distribution strategies are episodically intersecting with Industry 4.0, mostly in relation to data analytics and artificial intelligence. As such, the operative OM activities and the respective decision-support methods, especially in manufacturing and logistics are likely to be significantly transformed through I4.0 in the near future. Engineering technologies and infrastructure of Industry 4.0 are mainly utilized in manufacturing. Data processing technologies are mostly applied to planning and sourcing decision-making domains. In the logistics area (both intralogistics and cross-company logistics), the communication component of Industry 4.0 notably dominates.

The literature in the organizational stream points to the development of new business models for supply chain and operations. I4.0 enables transformations from "static" make and deliver systems with fixed entities to "dynamic" digitally designed and operated dynamic networks with changing membership. Although OM research in I4.0 appears more closely associated with the management and organizational streams, the technology stream does include industrial engineering and data science research in topics closely related to $\mathrm{OM}$. As such, it is necessary to focus on multi-disciplinary perspectives since I4.0 is likely to bring distinctive disciplinary specifics in OM research. In doing so, OM managers can explore broader issues and develop more robust and novel methods for decision-making support.

\section{Survey results and analysis}

To complement our literature analysis, we surveyed researchers from different disciplines who involved in different types of I4.0 research as shown in Fig. 1. Besides understanding different perspectives on I4.0 from different research disciplines, we are interested in examining our second research question: "What are the differences and consistencies in focus and perspective in research on I4.0 across different OM related disciplines (engineering, management, control, and data science)?” Our intent is to combine our survey analysis and literature analysis to identity research opportunities in I4.0 for OM researchers. Guided by our research questions and the literature analysis, we designed a questionnaire (Appendix 1) to tease out interdisciplinary commonalities and differences in I4.0 research, including research methods and research opportunities.

\subsection{Survey objectives and setup}

Associated with the $9^{\text {th }}$ IFAC MIM 2019 Conference held in Berlin, we conducted a survey of 238 researchers in the areas of automatic control (44 respondents), computer and data science (12 respondents), industrial and mechanical engineering (IME; 144 respondents), operations research (OR, 92 respondents), and OM (216 respondents) (see Appendix 1 for survey structure and Appendix 2 for detailed survey results; multiple selections of disciplines have been allowed).

The objective of the survey was to discern diverse research streams in I4.0 within the community of OM researchers and develop a distinguishing structure for research analysis. Notably, we try to go beyond existing knowledge and proactively predict promising directions for future research on I4.0. MIM 2019 is uniquely multi-disciplinary, and therefore it is a great platform for conducting such a survey. Another fea- 
ture of the MIM 2019 is its strong international focus with participants from 51 countries from all 7 continents. We have received 204 responses from the MIM conference participants and 34 additional responses from the senior researchers from our own network working in the I4.0 area, in total 238 responses from 43 countries (Figure 3).

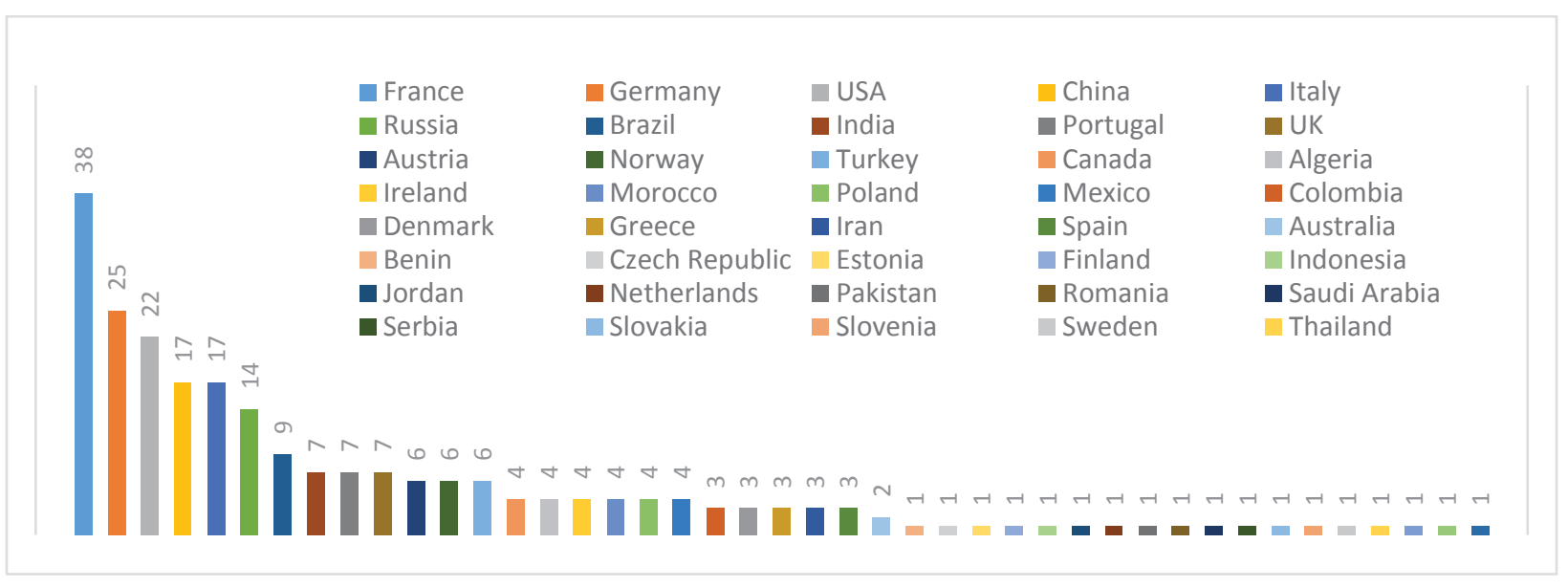

Figure 3. Geographies of survey participants.

The 10 most represented countries are France (38), Germany (25), USA (22), China (17), Italy (17), Russia (14), Brazil (9), India (7), Portugal (7), UK (7). In terms of the continents, we obtained 152 responses from Europe (64\% out of total number of responses), 34 from Asia (14\%), 30 from North America (13\%), 13 from South America (5\%) and 10 from Africa (4\%).

\subsection{Survey results}

In this section, we focus on the outcomes of our survey and present the analysis. The detailed statistics are presented in Appendix 2.

\section{Q1: In which industry sector do you see significant adoptions of Industry 4.0 in your country?}

According to the researchers' opinions, I4.0 applications are seen mainly in automotive, logistics, ICT technological services, machinery and healthcare. At the same time, such sectors as food and beverage, fashion, metalworker and chemistry still lack innovative I4.0 developments. Appendix 2 shows more details.

\section{Q2: What are the significant limitations that inhibit the adoption of Industry 4.0 in your country?}

The response provided by our respondents suggest that an inadequate understanding of I4.0, lack of strategic vision, lack of competent staff, worker reskilling needs, and lack of access to capital comprising the primary limitations. Literature parallels such concerns. Past research identifies high investment needs for I4.0 implementation, lack of clarity regarding economic benefit, challenges in value-chain integration, lack of infrastructure and lack of digital skills and digital culture as critical constraints to I4.0 adoption (Raj et al, 2019, Frank et al. 2019). Details are available in Appendix 2,

\section{Q3: Which of the following Industry 4.0 technologies have you investigated/tested/implemented in the last 2 years?}

The response is provided in Figure 4 that is broken down by the respondent's discipline. Figure 4 and Appendix 2 suggest that big data analytics, artificial intelligence and CPS (cyber physical systems) are among the most researched I4.0 technologies across the disciplines. Data monitoring and control is another I4.0 area seen to attract research attention. At the same time, I4.0 technologies such as additive manufacturing, augmented reality and collaborative robots seem relatively under-researched. Inter-disciplinary diversity in I4.0 technological adoption is evident. While the IME discipline has largely focused on the research engineering technologies such as CPS, robots, augmented reality, and additive manufacturing, OM is particularly attentive to such data science-related technologies such as big data analytics and artificial 
intelligence. Other data science technologies such as cyber-security do not seem to have received appropriate consideration among OM researchers. This result is in line with our literature analysis as reported in Section 2.

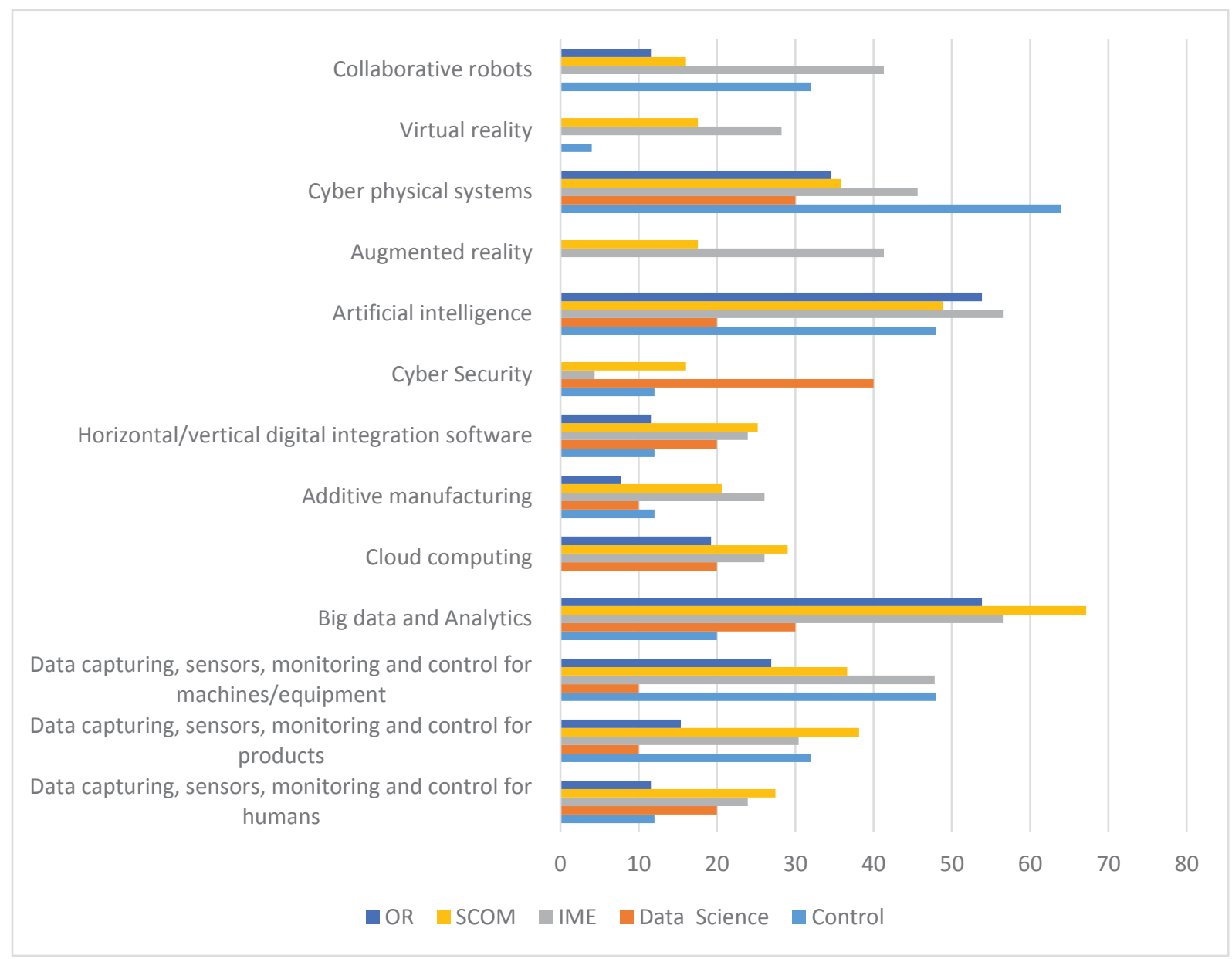

Figure 4. Cross-discipline statistics on the investigated/implemented Industry 4.0 technologies.

\section{Q4. Which of the following technologies/principles do you consider to be the closest to Industry 4.0?}

Figure 5 and Appendix 2 indicate that researchers' perspectives on I4.0 vary. Technologies such as CPS and IoT are of interest across almost all the disciplines. However, IME and control researchers emphasize the role of RMS/FMS, while OM researchers highlight the importance of cloud manufacturing (i.e., a model for enabling ubiquitous, convenient, on-demand network access to a shared pool of configurable manufacturing resources [...] that can be rapidly provisioned and released with minimal management effort or service provider interaction (Xu 2012)). 


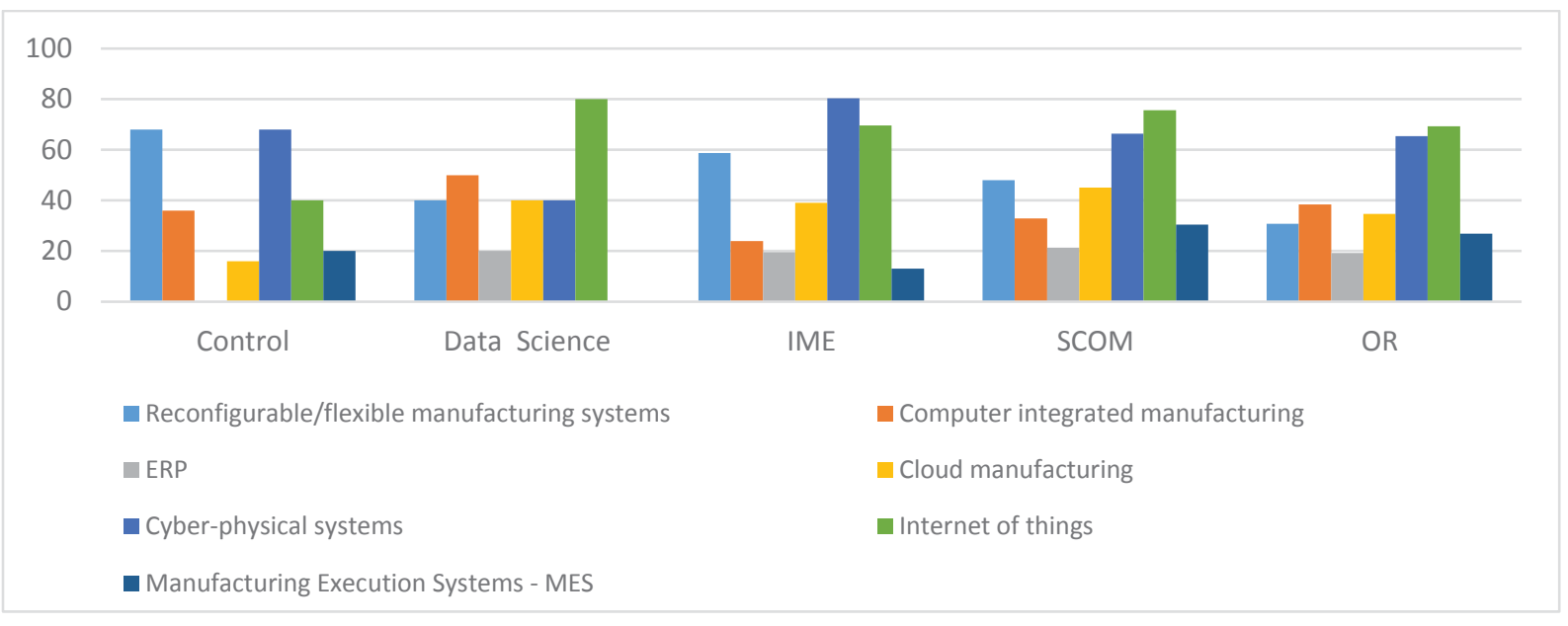

Figure 5. Cross-discipline statistics on the Industry 4.0 technologies.

\section{Q5. In your opinion, which areas in Industry 4.0 require urgent academic research attention?}

Figure 6 and Appendix 2 indicate some commonalities as well as differences in the researchers' views on priority I4.0 areas for investigation. OR specialists favor the new mathematical models for I4.0 as well as Resilience, the Ripple effect and Risk analysis in I4.0 systems. IME and control researchers point to the importance of the human aspects in I4.0 systems. Data science researchers prioritize the study of inhibitors and enablers of I4.0 as well as its practical implementation. OM researchers highlight the importance of cost-benefit computations, performance measurement, and practical implementation. These views are shared by other disciplines. Overall, practical implementation issues, performance and cost analysis, human factors, new mathematical models and resilience/risk are salient research topics arising from I4.0.

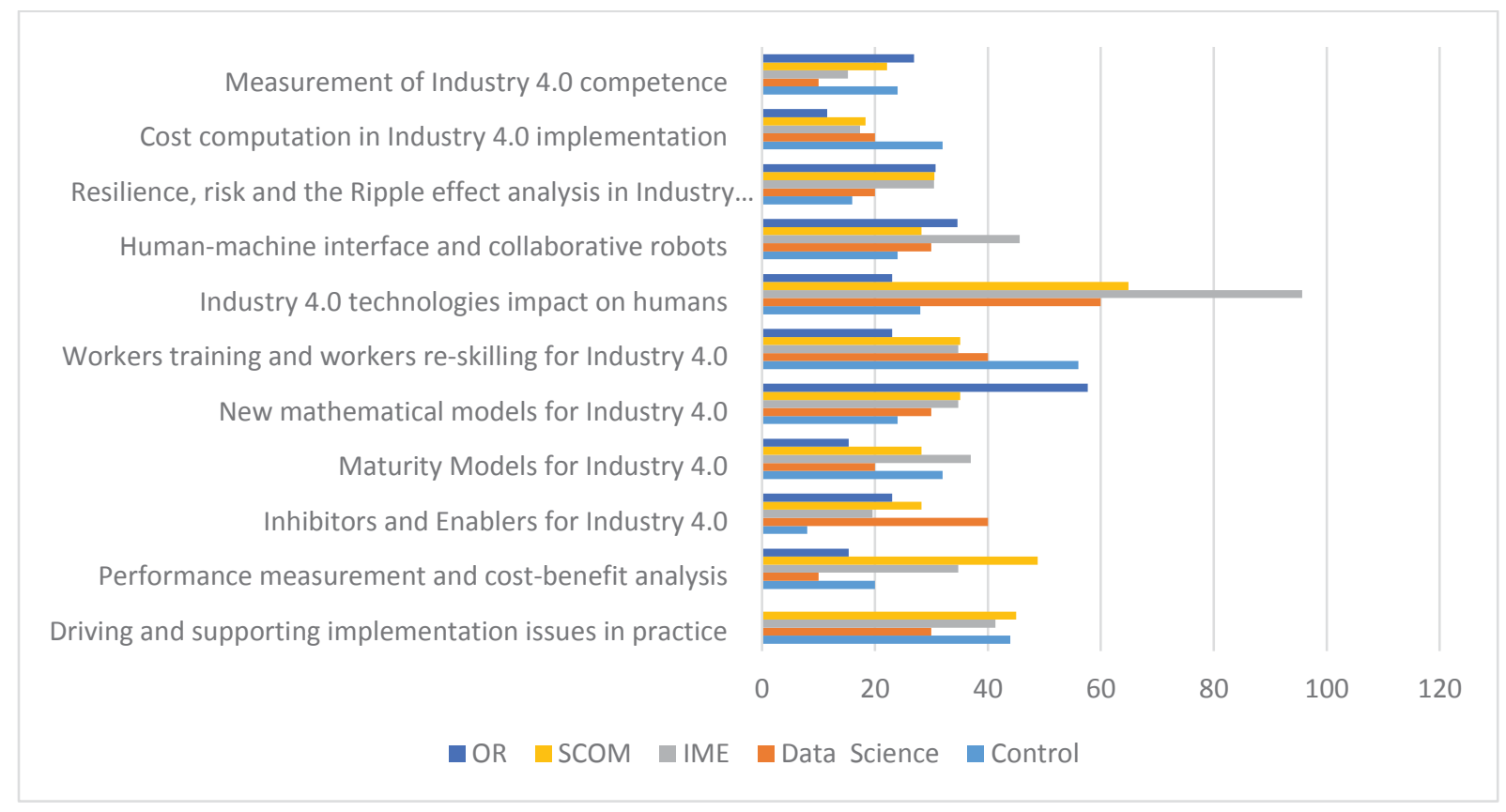

Figure 6. Cross-discipline statistics on the Industry 4.0 urgent research areas

\section{Q6. What about the next step? Which of the following paradigms do you consider to be the most suitable to be addressed in Industry 5.0?}

Figure 7 and Appendix 2 suggest that Human and machine intelligence alignment and creation of a collaborative industry using human-machine interfaces emerge as two major future research areas which will 
shape the transition to the next industrial "revolution", Industry 5.0. Other, important, enablers of this transition are seen in artificial intelligence, sustainability and circular economy, and SC resilience. SC resilience finds resonance especially among OM researchers, who also strongly favor sustainability and circular economy topics. Human-machine collaborations dominate IME researchers' perspectives, while data science specialists focus on artificial intelligence and sustainability, intersecting with OM perspectives. OR, control and IME share similar opinions in regard to human and artificial intelligence alignments.

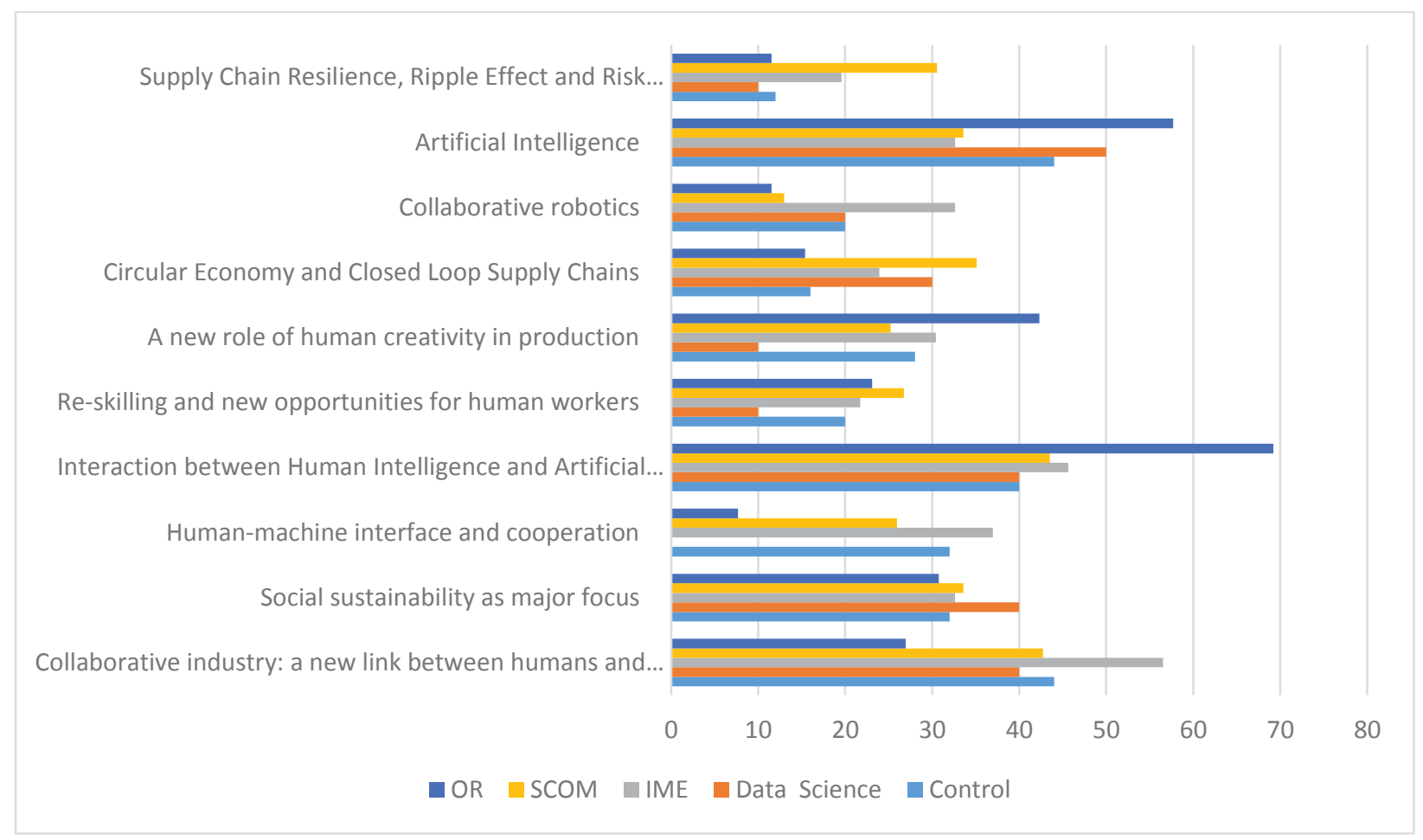

Figure 7. Cross-discipline statistics on the Industry 4.0 future research areas

\section{Q7. In your opinion, which methodologies seem particularly appropriate for such research?}

From Figure 8 and Appendix 2, we observe that case-studies are considered to be an important component of I4.0 research, especially among IME and OM researchers. OR specialists report optimization/simulation and data analytics as preferred research methods in solving I4.0-related decision-making problems. Experimental designs are emphasized by the control and IME community, while data science researchers highlight the importance of building conceptual frameworks and models.

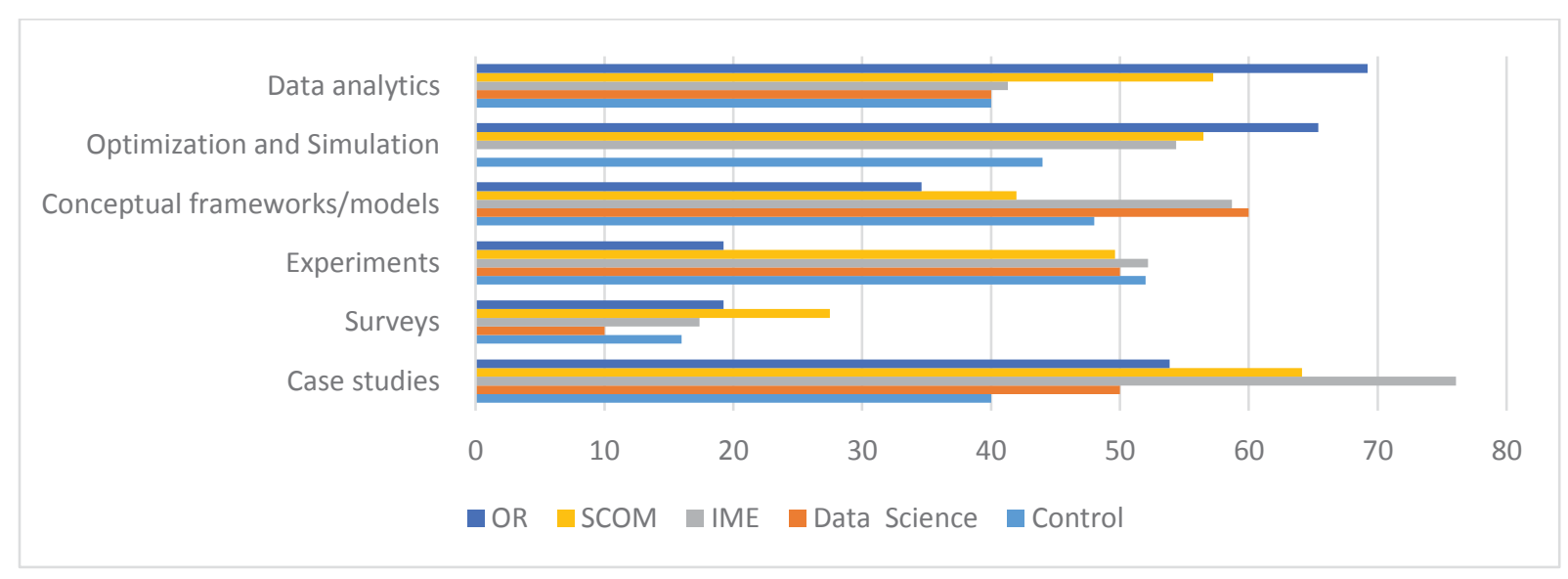

Figure 8. Cross-discipline statistics on the Industry 4.0 research methodologies

\subsection{Structuring the survey results}


We now structure our analysis of the survey responses according to the 3D I4.0 framework as presented in Figure 2 .

I4.0 management: OR specialists call for new mathematical models for supply chain resilience, the Ripple effect and risk analysis in I4.0 systems. Human aspects in manufacturing and man-machine interface in general shape the IME and control researchers' perspectives. Formation of self-organized and self-adaptive systems using human and artificial intelligence alignments are commonly seen in OR, control and IME, as new management principles associated with I4.0. Data science specialists mainly focus on artificial intelligence and sustainability, intersecting with $\mathrm{OM}$ perspectives. OM as well as data science researchers highlight the importance of cost-benefit computations, performance measurement, and practical implementation. Overall, practical implementation issues, performance and cost analysis, human factors, and resilience/risk are the main topics which researchers across the disciplines consider as the most urgent in the management domain of I4.0.

I4.0 organization: IME and control researchers underline the role of RMS/FMS as dominating manufacturing forms in I4.0 while OM researchers highlight cloud manufacturing in their responses. Across the disciplines, creation of a collaborative industry using human-machine interfaces, sustainability and circular economy, and resilience are seen by researchers as the most important and urgent research topics. Resilience is a popular I4.0 topic, especially OM researchers, who also strongly favor sustainability and circular economy topics. Human-machine collaborations predominate IME researcher perspectives, in terms of building new organizational frameworks in the era of I4.0.

I4.0 technologies: Big data analytics, artificial intelligence and CPS commonly mentioned I4.0 technologies across the research disciplines. Data monitoring and control have also been frequently applied in I4.0 research. The research engineering technologies such as CPS, robots, augmented reality, and additive manufacturing have mostly been adopted in IME, while data analytics technologies prevail in OM. Control specialists are mostly interested in CPS and data monitoring and control which feeds the major research streams in feedback-driven automated control. As such, the researchers' perspectives on I4.0 technologies are focused differently; though some commonalities can be observed such as a prevalence of CPS, IoT and data analytics across almost all the disciplines.

Further, we segment our analysis in terms of technological perspective (Q3 and Q4 of the MIM survey), future research perspectives (Q5 and Q6), and research methodologies (Q7). In general, the survey results (Q3-Q7) suggest that different disciplines have a shared understanding of future research topics and a common view on enabling technologies, but employ different methodological perspectives. Table 2 groups the findings.

Table 2. I4.0 research across the disciplines

\begin{tabular}{|l|l|l|l|}
\hline Disciplines & $\begin{array}{l}\text { Dominating Method- } \\
\text { ology }\end{array}$ & Technologies & Future research areas \\
\hline OM & Case studies & IoT/CPS & $\begin{array}{l}\text { Interaction between Human Intelligence and Artificial } \\
\text { Intelligence; } \\
\text { Collaborative industry: a new link between humans and } \\
\text { technologies }\end{array}$ \\
\hline OR & $\begin{array}{l}\text { Data analytics / Opti- } \\
\text { mization and Simula- } \\
\text { tion }\end{array}$ & IoT/CPS & $\begin{array}{l}\text { Interaction between Human Intelligence and Artificial } \\
\text { Intelligence; } \\
\text { Circular Economy and Closed Loop Supply Chains }\end{array}$ \\
\hline Control & Experiments & CPS/RMS & $\begin{array}{l}\text { Artificial Intelligence; } \\
\text { Collaborative industry: a new link between humans and } \\
\text { technologies }\end{array}$ \\
\hline IME & Case studies & $\begin{array}{l}\text { Collaborative industry: a new link between humans and } \\
\text { technologies; } \\
\text { Interaction between Human Intelligence and Artificial } \\
\text { Intelligence }\end{array}$ \\
\hline Data Science & $\begin{array}{l}\text { Conceptual frame- } \\
\text { works }\end{array}$ & IoT & $\begin{array}{l}\text { Artificial Intelligence; } \\
\text { Collaborative industry: a new link between humans and } \\
\text { technologies }\end{array}$ \\
\hline
\end{tabular}


Quoting Paul Valery ("Let us enrich ourselves with our mutual differences", https://best-quotations.com/authquotes.php?auth=30), and in light of recent studies by Kumar et al. (2018), Choi et al. (2018) and Cachon et al. (2020) advocating multi-disciplinary research in OM, we consider multi-disciplinary collaboration as a key to further OM developments in the era of I4.0. Linking the ensuing discussion to Table 2 and our analysis of responses to Q3-Q7 in Sect. 3.2, we provide some reasoned conjectures of possible cross-disciplinary collaborations for selected OM topics.

Table 2 indicates that I4.0 development may be particularly attentive to interactions between human intelligence and artificial intelligence along with collaborative industry on the basis of human-machine systems. Multi-methodological approaches would dominate, including conceptual frameworks, case-studies, experiments, data-driven and model-driven decision-making support. More comprehensively, the five major research areas and five major disciplines involved with I4.0 research can be classified as shown in Figure 9 below.

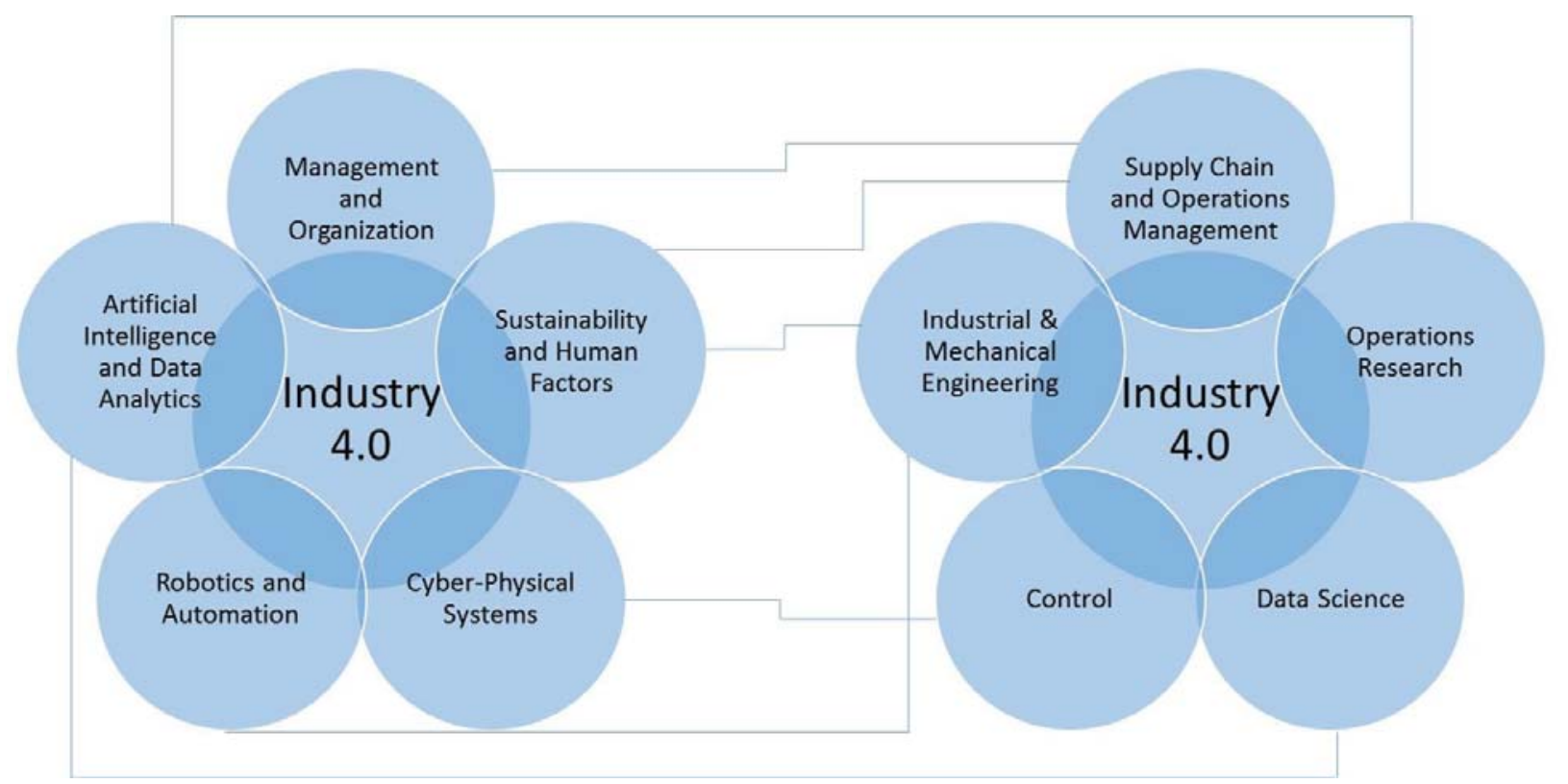

Research areas in I4.0

Research disciplines in I4.0

\section{Figure 9. Research areas and disciplines in I4.0}

Management and organization, robotics and automation, artificial intelligence and data analytics, sustainability and human factors, and CPS belong to I4.0 research areas. The research in these areas is split across different disciplines (some exemplary connections are shown in Figure 9). Obviously, multi-disciplinary collaborations are possible and useful, both within each of the research areas, as well as across the areas.

Figures 9 and Table 3 below combine the findings of our literature analysis and survey in order to highlight I4.0's impact on different OM decision-making areas, research opportunities and future research topics, and multi-disciplinary collaboration opportunities. Figure 10 summarizes major interrelations of management, technological and organizational research streams in Industry 4.0. Table 3 summarizes Industry 4.0's impact on $\mathrm{OM}$ decision-making. 


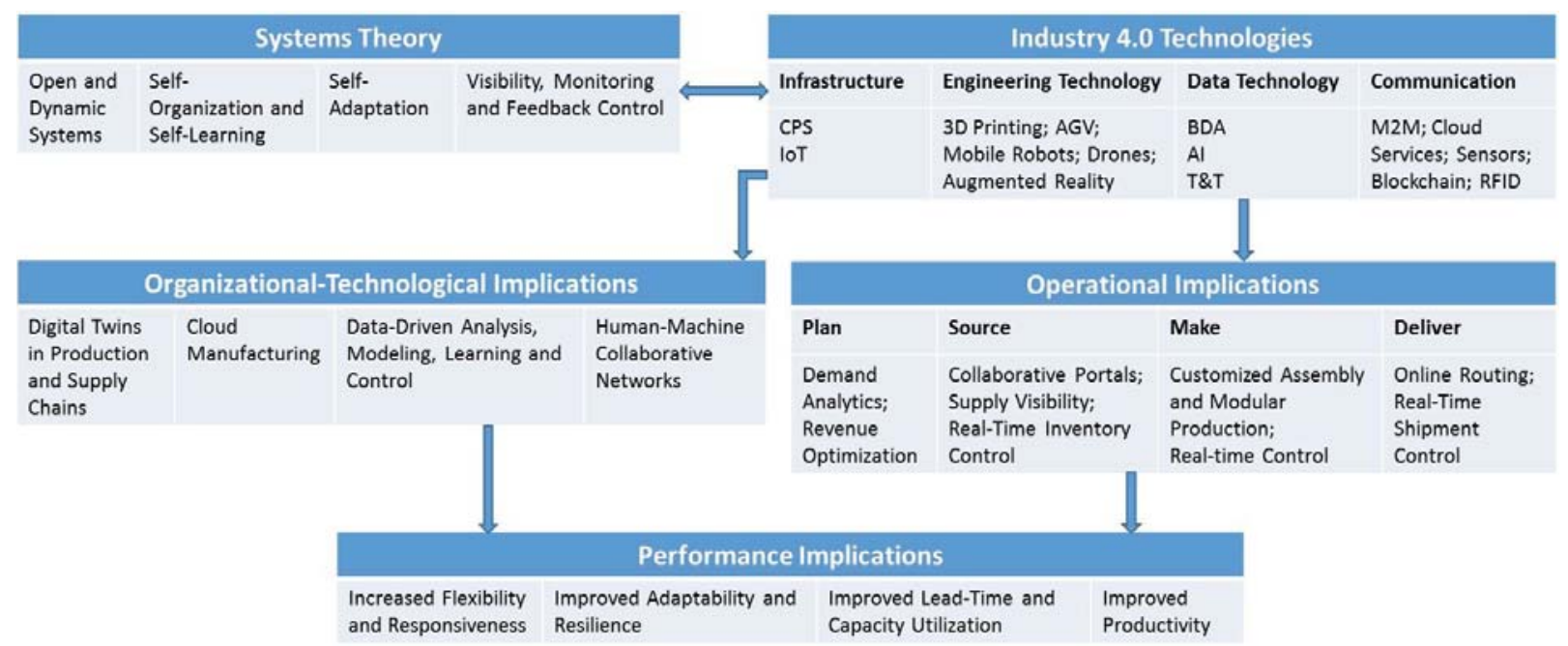

Figure 10. Interrelations of management, technological and organizational research streams in Industry 4.0.

Figure 10, in line with our literature analysis and the 3D-framework of I4.0 (cf. Figure 1), depicts major implications of I4.0 from the management, organizational and operational perspectives. We see that I4.0 draws on fundamental systems theory principles such as formation of open and dynamic systems, selforganization, self-adaptation and self-learning as well as visibility, monitoring and feedback control. Figure 10 classifies the I4.0 framework into four areas, i.e., infrastructure, engineering technology, data technology and communication. I4.0 opens new organization-technological designs such as cloud manufacturing, digital twins, data-driven modelling and collaborative industry. At the operational level, we classify the I4.0 implications per the SCOR processes (plan-source-make-deliver). Finally, Figure 10 identifies the major performance implications of utilizing I4.0, as gathered from our literature review and survey data. Fig. 9 also adds new elements to OM. These include new organizational level principles to aid design supply chains and operations, as well as operational level decision-making methods and models for planning, sourcing, production, and logistics.

\section{Insights and $O M$ research opportunities}

This section highlights major insights and research opportunities for OM revealed by our study related to our third research question: "What are the topics and research opportunities for OM in I4.0?"

Insight 1: The impact of I4.0 on OM are mostly prevalent in the operative areas as well as areas close to manufacturing activities such as production planning and control, inventory management, process design. Strategic decisions outside the production area are episodically intersecting with Industry 4.0, mostly in relation to data analytics and artificial intelligence.

Research opportunities 1: Strategic and tactical OM decision-making levels lack I4.0 considerations. One should examine different I4.0 components at the levels of IT infrastructure, engineering technologies, data technologies and communication technologies and enhance OM by developing new business models of I4.0 and therefore extend the research scope from operative level of I4.0 utilization towards the tactical and strategic decision-making. Another emerging research area with intersections of I4.0 and strategic OM decisions is re-designing of the supply chains following the COVID-19 pandemic impacts. Numerous I4.0 technologies such as robotics and additive manufacturing can support localization of supply chains which in turn, can be expected to increase resilience and reduce risks stemming from the global network designs.

Insight 2: While strategic OM decision-making areas have only episodically intersections with I4.0, the operative OM activities and the respective decision-support methods, especially in manufacturing and logistics, are likely to be significantly transformed through I4.0. While production-oriented areas are mainly utilizing engineering technologies and infrastructure of I4.0, the planning and sourcing decision-making domains take advantage of data processing technologies. In the logistics area (both intralogistics and crosscompany logistics), the communication part of Industry 4.0 notably dominates. 
Research opportunities 2: Production, sourcing and logistics decision-making areas use I4.0 technologies fragmentarily. Specifically, production planning and control is influenced by the technical I4.0 infrastructure such as CPS, IoT, additive manufacturing, mobile robots, and M2M communication. Sourcing, transportation and sales are transformed by data analytics and artificial intelligence components of I4.0 as well as communication technologies such as cloud services, blockchain, smart products and RFID. One should consider in the next step integrated supply chain view - a digital supply chain - that aligns I4.0 usage along the value-adding chain.

Insight 3: New disruptive supply chain business models that do not rely on a rigid physical system with a fixed and static activities. Instead, different physical enterprises will offer services in supply, manufacturing, logistics, and sales which will result in the dynamic allocation of processes and dynamic supply chain structures.

Research opportunities 3: A strong focus on descriptive analysis predictive models, and prescriptive models is necessary. This calls for multi-disciplinary collaborations with engineering, data science and control disciplines. Multi-disciplinary research can help in enhancing the predictive OM decision-support models towards real-time based, prescriptive methods. Collaboration across the disciplines can help to extend the current understanding of decision-support systems towards decision analysis, modelling, control and learning systems (DAMCLS).

Insight 4: Engineering and information science disciplines dominate the I4.0 research with strong emphasis on technologies and their advances. The business models and accompanying organizational and management principles are understood vaguely across different disciplines. For example; Mittal et al. (2018) and Yin et al. (2018) focused on the role of leadership, market aspects and operational capabilities required for I4.0 adoption.

Research opportunities 4: I4.0 technologies are mostly applied to the existing business models, organizational principles and management problem settings. The paucity of research on I4.0-specific, novel decision-making settings can be observed in OM. This is undoubtedly a research gap since I4.0 technology adoptions are being accompanied by organizational changes and the resulting OM transformations which cannot be neglected. A clear understanding of the ongoing transformations in I4.0 and the resulting consequences for OM can be difficult without a coherent, cross-disciplinary view on I4.0 and utilizing the underlying systemic principles of self-organization, self-adaptation, and self-learning.

We conclude this section by using our literature analysis and survey to establish some potential intersections of interest between various OM areas and research disciplines in the I4.0 context (Table 3). We classify each cell in Table 3 according to our findings in our literature analysis and survey as follows:

1. SL: the intersection relationship has been identified in our literature analysis and survey

2. S: the intersection relationship has been identified in the survey but not found in the literature

3. Blank: there is a potential relationship that has not been identified in the survey nor in our literature analysis

Based on our classification scheme, the cells marked with "LS" can be interpreted as the current state of I4.0 research; the cells marked with "S" represent the research gaps (i.e., a topic identified by our respondents and yet it is not find in the literature); and those blank cells can be viewed as potential future research topics. Let us consider some illustrative examples. Notice that process design and production planning and control require considerations of CPS and IoT along with M2M, cloud manufacturing services and smart products. As such, a collaboration between OM researchers and researchers in the IME, data science and control disciplines will be a great step forward. Next, observe that new sourcing and distribution strategies can be developed with the use of additive manufacturing, blockchain and artificial intelligence, calling for a closer collaboration between OM researchers and researchers in IME and data sciences. 


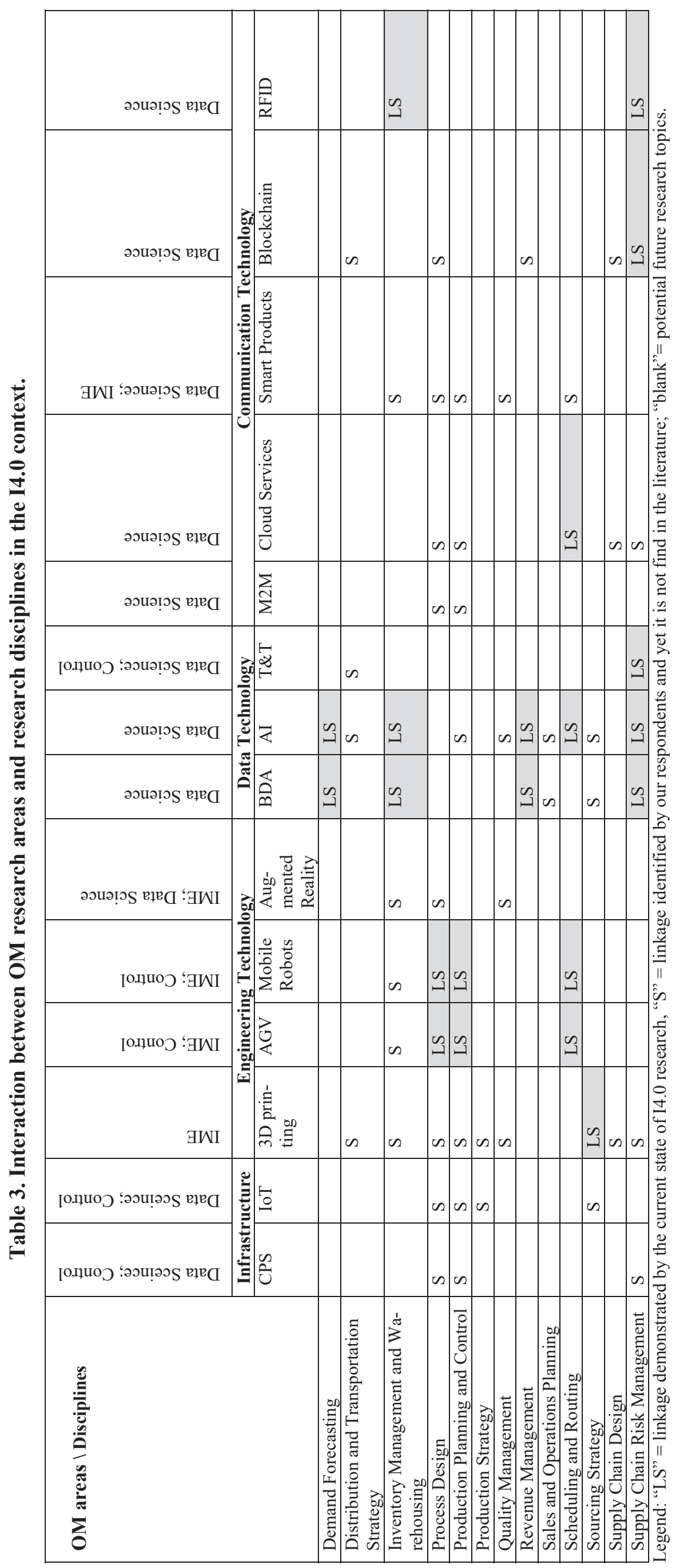




\section{Conclusion}

The term I4.0 has been used in a wide range of research fields and disciplines so far. These disciplines handled I4.0 differently and sometimes even deviating from its initial meaning. Relying on one of the largest data sets of researchers' perspectives collected to date and a thorough literature analysis, we provide a timely assessment of the OM field in the era of I4.0, illustrate its future potential, and motivate OM scholars for research advancements in exciting area.

Our literature analysis and survey results clearly indicate that theory, methodologies, and applications in I4.0 cut across the fields of industrial and mechanical engineering, operations research, OM, information systems, data science and analytics, management science, and social and cognitive sciences. We summarize the main results of our study according to three research question formulated in the introduction.

Through our study, we find that OM research belong to major clusters in Industry 4.0; however, we identify the prevalence of industrial engineering and data science research in the topics closely related to OM. As such, it is necessary to focus on multi-disciplinary perspectives since I4.0 is likely to bring distinctive specifics in OM research which can be examined by using more than one research method. In doing so, OM decision-makers can explore broader issues and develop more robust and novel methods for decision-making support.

In our survey on the I4.0 topics among researchers in industrial engineering, OM, operations research, control and data science, we find the researchers 'opinions on the current use of research methodologies and the underlying technologies, as well as perceived benefits and barriers. In addition, we highlight the most significant outcomes of research projects in I4.0 obtained to the date along with the areas which require urgent academic attention. The results depict that while strategic OM decision-making areas have only episodically intersections with I4.0, the operative OM activities and the respective decision-support methods, especially in manufacturing and logistics are likely to be significantly transformed through I4.0. Specifically, production planning and control will be influenced by the technical I4.0 infrastructure such as CPS, IoT, additive manufacturing, mobile robots and cobots, and M2M communication. Sourcing, transportation and sales are likely to be transformed by data analytics and artificial intelligence components of I4.0 as well as communication technologies such as cloud services, blockchain, smart products and RFID. Finally, a strong focus on descriptive analysis and a lack of predictive and real-time, prescriptive models has been revealed calling for multi-disciplinary collaborations with engineering, data science and control disciplines.

Finally, through our examination we illustrate how different disciplines understand and investigate OM problem in the I4.0 era, and how they can complement each other. Multi-disciplinary research can help in enhancing the predictive OM decision-support models towards real-time based, prescriptive methods. Collaboration across the disciplines can help to extend the current understanding of decision-support systems towards decision analysis, modelling, control and learning systems (DAMCLS). One should examine different I4.0 components at the levels of IT infrastructure, engineering technologies, data technologies and communication technologies and enhance OM by developing new business models of I4.0 and therefore extend the research scope from operative level of I4.0 utilization towards the tactical and strategic decisionmaking.

In closing, we would like to note that several possible developments in adapting OM to the realities of I4.0 lay ahead, and studying these phenomena is extremely important both for academia and industry and society. OM is one of the fundamental elements of I4.0 which role and contributions to the field need to be strengthened and made visible to other disciplines. At the same time, OM researchers and practitioners can enhance their knowledge and utilize the I4.0 potentials to the highest extents when collaborating and acquiring the knowledge in data sciences and engineering. It could be interesting to undertake a quantitative comparison of how each research field has been developed through I4.0 over time. This would help to observe which field is really related to I4.0 in terms of change. Such an analysis could support projections of further future research streams. Moreover, the COVID-19 pandemic - the unprecedented challenge for 
manufacturing industry - has clearly shown and highlighted the importance of I4.0 and cloud manufacturing, proactive scheduling and SC mapping (Sokolov et al. 2020, Queiroz et al. 2020). Firms with established technologies for manufacturing visibility and digital control were able to react to disruptions more flexible and responsive. This newly emerged tension of digitalization and resilience represents a promising future research avenue.

\section{Acknowledgements}

We cordially thank all the participants of the IFAC MIM 2019 conference for contributing their valuable time and expertise to the survey presented in this paper.

\section{Funding}

This research has been funded by the European Union's Horizon 2020 research and innovation programme under the Marie Sklodowska-Curie grant agreement No 873077 (MAIA-H2020-MSCA-RISE 2019).

\section{References}

1. Alcácer V., V.Cruz-Machado (2019). Scanning the Industry 4.0: A Literature Review on Technologies for Manufacturing Systems. Engineering Science and Technology: an International Journal, 22(3), 899-919.

2. Aldrighetti R, Zennaro I, Battini D, Finco S (2019). Healthcare Supply Chain Simulation with Disruption Considerations: A Case Study from Northern Italy. Global Journal of Flexible Systems Management, 20, 81-102, 10.1007/s40171-019-00223-8.

3. Amaral LAN, Uzzi B (2007) Complex system - a new paradigm for the integrative study of management, physical, and technological systems. Manag Sci 53:1033-1035

4. Anderson P (1999) Complexity theory and organization science. Organ Sci 10:216-232

5. Ashby WR (1956) An introduction to cybernetics. Chapman \& Hall, London

6. Audi (2019). Flexible Montage in der Fahrzeugproduktion Die flexible Audi R8-Manufaktur mit fahrerlosen Transportfahrzeugen. https://www.plattform-i40.de/PI40/Redaktion/DE/Anwendungsbeispiele/137-wandelbare-r8-manufaktur/beitrag-wandelbare-r8-manufaktur.html, accessed on October 4, 2019

7. Barabasi AL (2005) Network theory - the emergence of the creative enterprise. Science 308:639-641

8. Basole, R.C., Bellamy, M.A. (2014) Supply Network Structure, Visibility, and Risk Diffusion: A Computational Approach. Decision Sciences, 45(4), 1-49.

9. Beer, S. (1985). Diagnosing the system for organisations. Chichester: Wiley.

10. Bellmann R (1972) Adaptive control processes: a guided tour. Princeton Univ. Press, Princeton, New Jersey

11. Ben-Daya, M., Hassini E., \& Bahroun Z. (2019). Internet of things and supply chain management: a literature review. International Journal of Production Research, 57(15-16), 4719-4742.

12. Bertalanffy von, Ludwig (1969) General System Theory, George Braziller.

13. Bordoloi, S.K., Cooper, W.W., Matsuo, H (1999). Flexibility, adaptability, and efficiency in manufacturing systems. Production and Operations Management, 8(2), 133-149.

14. Buer S-V, Strandhagen JO, Chan F.T.S. The link between Industry 4.0 and lean manufacturing: mapping current research and establishing a research agenda. Int J Prod Res, 2017;56(8):2924-40.

15. Cachon GP, Girotra K., Netessine, S. (2020). Interesting, Important, and Impactful Operations Management. Manufacturing Service and Operations Management, 22(1), 214-222.

16. Calzavara M, Battini D, Bogataj D, Sgarbossa F \& Zennaro I (2020) Ageing workforce management in manufacturing systems: state of the art and future research agenda, International Journal of Production Research, 58:3, 729-747.

17. Camarinha-Matos, L.M. (2009), "Collaborative networked organizations: Status and trends in manufacturing”, Annual Reviews in Control Vol. 33 No. 2, pp. 199-208.

18. Casti JL (1979) Connectivity, complexity and catastrophe in large-scale systems. Wiley-Interscience, New York and London 
19. Cavalcantea, I.M., Frazzon E.M., Forcellinia, F.A., Ivanov, D. (2019). A supervised machine learning approach to data-driven simulation of resilient supplier selection in digital manufacturing. International Journal of Information Management, 49, 86-97.

20. Choi TY, Dooley KJ, Rungtusanatham M (2001) Supply networks and complex adaptive systems: control versus emergence. J Oper Manag 19(3):351-366

21. Choi, T. M., Wallace, S. W., \& Wang, Y. (2018). Big data analytics in operations management. Production and Operations Management, 27(10), 1868-1883.

22. Chou MC, Chua G, Teo CP, Zheng H. (2010) Design for process flexibility: Efficiency of the long chain and sparse structure. Operations Research, 58(1):43-58.

23. D'souza, D.E., F.P. Williams (2000) Towards a taxonomy of manufacturing flexibility dimensions. Journal of Operations Management, 18 (2000), pp. 577-593.

24. Das, A., Narasimhan, R., Talluri, D. (2006). Supplier integration: Finding an optimal configuration. J of Oper Mgt, 24(5), 563-582.

25. Dekkers, R. (2009), "Distributed Manufacturing as Co-Evolutionary System", International Journal of Production Research, Vol. 47 No. 8, pp. 2031-2054.

26. Demirezen, EM, S. Kumar, and B. Shetty (2019). Two Is Better Than One: A Dynamic Analysis of Value Co-Creation. Production and Operations Management, Forthcoming.

27. Disney, S.M., D.R. Towill (2003). Vendor-managed inventory and bullwhip reduction in a two-level supply chain. International Journal of Operations \& Production Management, 23(6), 625-651.

28. Dolgui A., Ivanov D., Potryasaev S., Sokolov B., Ivanova M., Werner F. (2020). Blockchain-oriented dynamic modelling of smart contract design and execution control in the supply chain. International Journal of Production Research, 58(7), 2184-2199.

29. Dolgui, A., Ivanov, D., Sethi S.P., Sokolov, B. (2019). Scheduling in production, supply chain and Industry 4.0 systems by optimal control. Int J of Prod Res, 57(2), 411-432

30. Dubey R., Gunasekaran A., Childe, S. J. Wamba S.F., Roubaud D., Foropon C. (2019a). Empirical Investigation of Data Analytics Capability and Organizational Flexibility as Complements to Supply Chain Resilience. International Journal of Production Research, DOI: 10.1080/00207543.2019.1582820

31. Dubey, R., A Gunasekaran, SJ Childe, C Blome, T Papadopoulos (2019b). Big Data and Predictive Analytics and Manufacturing Performance: Integrating Institutional Theory, Resource-Based View and Big Data Culture. British Journal of Management 30(2), 341-361.

32. Fox MS, Barbuceanu M, Teigen R (2000) Agent-oriented supply chain management system. Int J Flex Manuf Syst 12:165-188

33. Fragapane G., Peron M, Sgarbossa F., Strandhagen J.O., Ivanov, D. (2020). Increasing flexibility and productivity in Industry 4.0 production networks with autonomous mobile robots and smart intralogistics. Annals of Operations Research, https://doi.org/10.1007/s10479-020-03526-7

34. Frank A.G., Dalenogare L.S., Ayala N.F. (2019). Industry 4.0 technologies: Implementation patterns in manufacturing companies. International Journal of Production Economics, 210, 15-26.

35. Fry MJ, Kapuscinski R., Olsen T.L. (2001). Coordinating Production and Delivery Under a (z, Z)Type Vendor-Managed Inventory Contract. Manufacturing and Service Operations Management 3(2), $89-173$.

36. Gao, J., Barzel, B., and Barabási, A.L. (2016). Universal Resilience Patterns in Complex Networks. Nature, 530(7590):307

37. Gunasekaran A, Ngai NWT (2009) Modeling and analysis of build-to-order supply chains. Eur J Oper Res 195(2):319-334

38. Ivanov D., Das, A., Choi T.-M. (2018). New Flexibility Drivers in Manufacturing, Service, and Supply Chain Systems, International Journal of Production Research, 56(10), 3359-3368.

39. Ivanov D., Dolgui, A. (2020) A digital supply chain twin for managing the disruption risks and resilience in the era of Industry 4.0. Production Planning and Control, DOI: 10.1080/09537287.2020.1768450.

40. Ivanov, D. (2018). Structural Dynamics and Resilience in Supply Chain Risk Management. Springer, New York.

41. Ivanov, D., Dolgui, A., Sokolov, B. (2019). The impact of digital technology and Industry 4.0 on the ripple effect and supply chain risk analytics. Int. Journal of Prod. Research, 57(3), 829-846. 
42. Ivanov, D., Dolgui, A., Sokolov, B., Werner, F., Ivanova, M. (2016). A dynamic model and an algorithm for short-term supply chain scheduling in the smart factory Industry 4.0. International Journal of Production Research, 54 (2): 386-402.

43. Ivanov, D., Sethi S., Dolgui A., Sokolov, B. (2018). A survey on the control theory applications to operational systems, supply chain management and Industry 4.0. Annual Reviews in Control, 46, 134147.

44. Ivanov, D., Sokolov B. (2012) The Inter-Disciplinary Modelling of Supply Chains in the Context of Collaborative Multi-Structural Cyber-Physical Networks, Journal of Manufacturing Technology Management, Vol. 23(8), 976-997.

45. Ivanov, D., Sokolov, B. (2010). Adaptive Supply Chain Management, London et al., Springer

46. Ivanov D., Dolgui A. (2020b). Viability of Intertwined Supply Networks: Extending the Supply Chain Resilience Angles towards Survivability. A Position Paper Motivated by COVID-19 Outbreak. International Journal of Production Research, 58(10), 2904-2915.

47. Ivanov D. (2020). Viable Supply Chain Model: Integrating Agility, Resilience and Sustainability Perspectives. Lessons From and Thinking Beyond the COVID-19 Pandemic. Annals of Operations Research, DOI: 10.1007/s10479-020-03640-6

48. Jabbour, ABL de Sousa, Jabbour, CJC., Filho,M.G., Roubaud D. 2018. Industry 4.0 and the circular economy: a proposed research agenda and original roadmap for sustainable operations. Annals of Operations Research 270 (1-2), 273-286.

49. Johnson, K., A. B. H. Lee and D. Simchi-Levi (2016), Analytics for an Online Retailer: Demand Forecasting and Price Optimization. Manufacturing and Service Operations Management. 18(1), 69-85.

50. Jordan, W.C. and Graves, S.C. (1995). On the principles of the benefits of manufacturing process flexibility. Management Science, 41, 577-594.

51. Koren, Y., U. Heisel, F. Jovane, T. Moriwaki, G. Pritschow, G. Ulsoy, H. Van Brussel (1999). Reconfigurable Manufacturing Systems. CIRP Annals, 48(2), 527-540.

52. Kumar, N., L. Qiu, and S. Kumar (2018). Exit, Voice, and Response in Digital Platforms: An Empirical Investigation of Online Management Response Strategies. Information Systems Research, 29(4), 849-870.

53. Kumar, S., V. Mookerjee, and A. Shubham (2018). Research in Operations Management and Information Systems Interface. Production and Operations Management, 27(11), 1893-1900.

54. Kusiak, A. (2018) Smart Manufacturing, International Journal of Prod Res. 56(1-2), 508-517.

55. Lee, H. and Özer,Ö. (2007) 'Unlocking the value of RFID'. Production and Operations Management, 16(1), 40-64.

56. Li J., Jia G., Cheng Y., Hu Y. (2017). Additive manufacturing technology in spare parts supply chain: a comparative study. International Journal of Production Research, 55(5), 1498-1515.

57. Liao, Y., Deschamps, Y., de Freitas, E., Loures R., \& LFP Ramos (2017). Past, present and future of Industry 4.0 - a systematic literature review and research agenda proposal. International Journal of Production Research, 55(12), 3609-3629.

58. Lin, S. and Visich, J.K. (2006). Radio frequency identification: supply chain impact and implementations challenges. International Journal of Integrated Supply Management, 2(4), 407-424.

59. Liu, Y., Wang, L., Wang, X.V., Xu X. \& L. Zhang (2019) Scheduling in cloud manufacturing: stateof-the-art and research challenges, International Journal of Production Research, 57(15-16), 48544879

60. Luthra, S., A. Kumar, E. K. Zavadskas, S. K. Mangla \& J. A. Garza-Reyes (2019). Industry 4.0 as an enabler of sustainability diffusion in supply chain: an analysis of influential strength of drivers in an emerging economy. International Journal of Production Research, 58(5), 1505-1521.

61. Machado CG., Winroth MP., da Silva EHDR (2020). Sustainable manufacturing in Industry 4.0: an emerging research agenda. Int J of Prod Res, 58(5), 1462-1484.

62. Maruyama M (1963) The second cybernetics. Deviation amplifying mutual causal process. Am Sci 51:164-179

63. Mesarovic MD and Takahara Y (1975) General systems theory: mathematical foundations. Academic Press, New York, Can Francisco, London.

64. Meyer, G. G., Buijs, P., Szirbik, N.B. and Wortmann, J.C. (Hans). 2014, "Intelligent products for enhancing the utilization of tracking technology in transportation", International Journal of Operations \& Production Management, 34:4, pp. 422-446. 
65. Mittal, S., Khan MA., Romero D., Wuest T. (2018) A critical review of smart manufacturing \& Industry 4.0 maturity models: Implications for small and medium-sized enterprises (SMEs). Journal of Manufacturing Systems, 49, 194-214.

66. Moghaddam, M., and S. Y. Nof (2018) "Collaborative service-component integration in cloud manufacturing." International Journal of Production Research 56(1-2): 677-691.

67. Muhuri PK., Shukla AK., Abraham A. (2019). Industry 4.0: A bibliometric analysis and detailed overview. Engineering Applications of Artificial Intelligence, 78, 218-235.

68. Nair, A., J.M. Vidal (2011). Supply network topology and robustness against disruptions - An investigation using a multi-agent model, International Journal of Production Research, 49(5), 1391-1404.

69. Nayak, A., R. Reyes Levalle, S. Lee \& S. Y. Nof (2016). Resource sharing in cyber-physical systems: modelling framework and case studies. International Journal of Production Research, 54(23), 6969-6983.

70. Nof, S.Y., "Collaborative control theory for e-work, e-production, and e-service, Ann Reviews in Control, 31(2), 2007, 281-92.

71. Nof, S.Y., Morel, G., Monostori, L., Molina, A., and Filip, F., "From Plant and Logistics Control to Multi-Enterprise Collaboration," Annual Reviews in Control, 30(1), 2006, pp. 55-68.

72. Oesterreich T.D., Teuteberg F. (2016). Understanding the implications of digitisation and automation in the context of Industry 4.0: A triangulation approach and elements of a research agenda for the construction industry. Computers in Industry, 83, 121-139.

73. Olsen T.L., Tomlin B. (2020). Industry 4.0: Opportunities and Challenges for Operations Management. Manufacturing and Service Operations Management, 22(1), 113-122.

74. Oztemel E., Gursev, S. (2020). Literature review of Industry 4.0 and related technologies. Journal of Intelligent Manufacturing, 31, 127-182.

75. Panetto H., Iung B., Ivanov D., Weichhart G., Wang X. (2019). Challenges for the cyber-physical manufacturing enterprises of the future. Annual Reviews in Control, 47, 200-213.

76. Papadopoulos, T., Gunasekaran, A., Dubey, R., Altay, N., Childe SJ, Wamba SF (2017). The role of Big Data in explaining disaster resilience in supply chains for sustainability. Journal of Cleaner Production, 142(2), 1108-1118

77. Park, H., MA Bellamy, RC Basole (2018). Visual analytics for supply network management: System design and evaluation. Decision Support Systems 91, 89-102.

78. Pathak SD, Day JM, Nair A, Sawaya WJ, Kristal MM (2007) Complexity and adaptivity in supply networks: building supply network theory using a complex adaptive systems perspective. Decis Sci 38 (4):547-580.

79. Piccarozzi, M., Aquilani, B., \& Gatti, C. (2018). Industry 4.0 in Management Studies: A Systematic Literature Review. Sustainability, 10(10), 3821.

80. Queiroz M.M., Ivanov D., Dolgui A., Fosso Wamba S. (2020). Impacts of Epidemic Outbreaks on Supply Chains: Mapping a Research Agenda Amid the COVID-19 Pandemic through a Struc-tured Literature Review. Annals of Operations Research, DOI: 10.1007/s10479-020-03685-7.

81. Raj, A., Dwivedi, G., Sharma, A., Jabbour ABL, Rajak, S. (2020). Barriers to the adoption of Industry 4.0 technologies in the manufacturing sector: An inter-country comparative perspective. Int J of Prod Econ, 224, 107546

82. Rossit, D.A., Tohmé F., \& M. Frutos (2019) Industry 4.0: Smart Scheduling, International Journal of Production Research, 57(12), 3802-3813.

83. Sari, K. (2008), "On the benefits of CPFR and VMI: a comparative simulation study", International Journal of Production Economics, Vol. 113 No. 2, pp. 575-586.

84. Schoenherr T., C. Speier-Pero (2015). Data Science, Predictive Analytics, and Big Data in Supply Chain Management: Current State and Future Potential. J of Business Logistics, 36(1): 120-132.

85. Siemens (2019). What doesn't happen keeps our world running smoothly - the power of MindSphere https://www.plm.automation.siemens.com/global/en/topic/mindsphere-whitepaper/28842 (accessed on November 18, 2019).

86. Slack N. (1987). The flexibility of manufacturing systems. International Journal of Operations and Production Management, 7(4), 35-45.

87. Sodhi MS, Son BG, Tang C (2012) Researchers' perspectives on supply chain risk management. Prod Oper Manag 21(1):1-13 
88. Sodhi MS., Tang C.S. (2012). Managing supply chain risk. Springer, NY

89. Sokolov B., Ivanov, D., Dolgui A. (Eds) (2020). Scheduling in Industry 4.0 and Cloud Manufacturing. Springer, New York, ISBN 978-3-030-43176-1.

90. Stadtler, H., Fleischmann, B., Grunow, M., Meyr, H., Sürie, C. (2012), Advanced Planning in Supply Chains, Springer, Berlin

91. Stecke, K. E. 1983. Formulation and Solution of Nonlinear Integer Production Planning Problems for Flexible Manufacturing Systems. Management Science 29 (3): 273-288.

92. Surana A, Kumara S, Greaves M, Raghavan UN (2005) Supply-chain networks: a complex adaptive systems perspective. Int J Prod Res 43(20):4235-4265

93. Swaminathan JM, Smith SF and Sadeh NM (1998) Modeling supply chain dynamics: a multiagent approach. Decis Sci 29(3):607-632

94. Tang C.S., Veelenturf L.P. (2019). The strategic role of logistics in the Industry 4.0 era. Transportation Research Part E: Logistics and Transportation Review, 129, 1-11.

95. Tao, F., Qi, Q., Liu, A., Kusiak, A. (2018). Data-driven smart manufacturing. Journal of Manufacturing Systems, 48(C), 157-169.

96. Tully S (1993) The modular corporation. Fortune 08.02.1993:52-56

97. Waller, M. A., and Fawcett, S. E. (2013). Data science, predictive analytics, and big data: a revolution that will transform supply chain design and management. J. of Bus Logistics, 34(2), 77-84.

98. Wamba, S. F., Ngai, E.W.T., Riggins, F. and Akter, S. (2017), "Transforming operations and production management using big data and business analytics: future research directions", International Journal of Operations \& Production Management, 37(1), 2-9.

99. Wamba, S.F. and Chatfield, A.T. (2009) 'A contingency model for creating value from RFID supply chain network projects in logistics and manufacturing environments', European Journal of Information Systems, Vol. 18, No. 6, pp. 615-636.

100. Warnecke HJ, Braun J (1999) Vom Fraktal zum Produktionsnetzwerk: Unternehmenskooperation erfolgreich gestalten. Springer-Verlag, Berlin, Heidelberg, New York

101. Wiendahl, H.-P., Reichardt, J., Nyhuis, P. (2015). Handbook Factory Planning and Design. Springer, Berlin.

102. Wiener, N. (1948). Cybernetics, or control and communication in the animal and the machine. The MIT Press, Cambridge, Massachusetts, 2nd Edition.

103. Xu L.D., Xu E.L., Li L. (2018). Industry 4.0: state of the art and future trends. Int J Prod Res, $56(8), 2941-62$.

104. Xu X. (2012). From cloud computing to cloud manufacturing. Robotics and Computer-Integrated Manufacturing 28, 75-86.

105. Xu, J., Tran, H.M., Gautam, N., Bukkapatnam, S.T.S. (2019) Joint production and maintenance operations in smart custom-manufacturing systems. IISE Transactions, 51(4), 406-421.

106. Yang, H., Kumara, S., Bukkapatnam, S.T.S, Tsung, F. (2019) The internet of things for smart manufacturing: A review. IISE Transactions, 51(11), 1190-1216.

107. Yao, Y., Kohli, R., Sherer, S.A. and Cederlund, J. (2013), "Learning curves in collaborative planning, forecasting, and replenishment (CPFR) information systems: an empirical analysis form a mobile phone manufacturer", Journal of Operations Management, Vol. 31 No. 6, pp. 285-297

108. Yin Y, Stecke K.E., Li D. (2018) The evolution of production systems from Industry 2.0 through Industry 4.0. Int J Prod Res, 56(1-2):848-861.

109. Zhao K., Zuo Z., Blackhurst J.V. (2019). Modelling supply chain adaptation for disruptions: An empirically grounded complex adaptive systems approach. J of Oper Management, 65(2), 190-212.

110. Zhong, R.Y., Xu, C., Chen, C., Huang, G.Q. (2017). Big Data Analytics for Physical Internet-based intelligent manufacturing shop floors. International Journal of Production Research, 55(9), 2610-2621.

111. Zhuge, H. (2011). Semantic linking through spaces for cyber-physical-socio intelligence: A methodology. Artificial Intelligence, 175(5-6), 988-1019.

112. Zühlke D. (2009). SmartFactory - A Vision becomes Reality. IFAC Proceedings Volumes, 42(4), pp. 31-39 


\section{Appendix 1. Questionnaire}

\section{Section 1}

\section{PERSONNAL INFORMATION}

Your name (optional):

Your affiliation (optional):

Your e-mail (if you wish to receive the results of this survey):

1. In which country are you located? *

2. Which of the following disciplines do you belong to? *

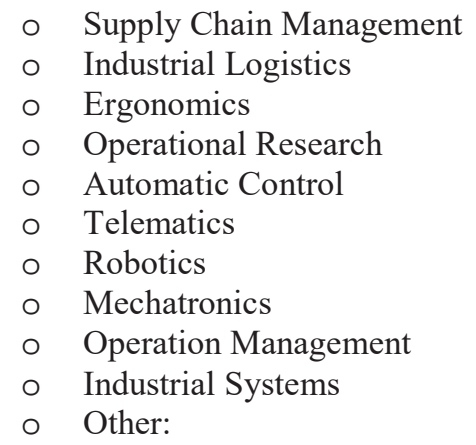

Section 2

\section{PRACTICAL EXPERIENCE IN I4.0}

3. Which industry sector do you see significant adoption of I4.0 in your country? *

- Building construction products and services;

- Chemistry and pharmaceuticals;

- Cement, manufactured and prefabricated parts, lime, bricks, glass and abrasives;

- Equipment for machinery;

$\circ$ Fashion;

- Food and beverage;

- Graphics, paper makers, paper converting

- Innovative and ICT technological services

- Marble;

- Rubber and plastic materials;

○ Metalworker;

$\circ$ Tanning;

○ Tourism;

- Transport and logistics;

- Automotive

○ Healthcare

- Other:

4. What are the significant limitations that inhibit the adoption of I4.0 in your country? *

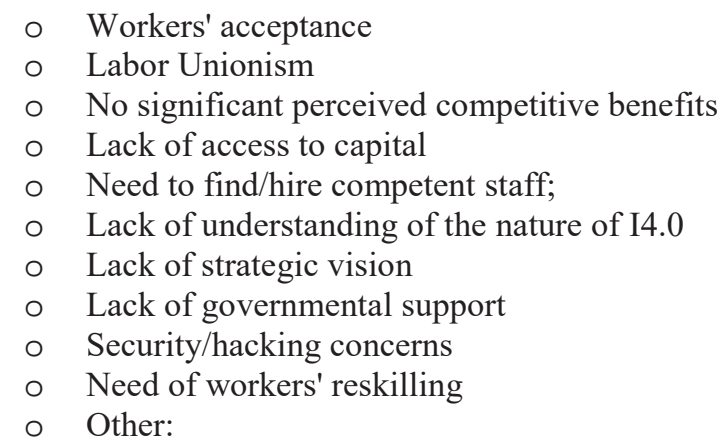

5. Which of the following I4.0 technologies have you investigated/tested/implemented in the last 2 years? *

- Data capturing, sensors, monitoring and control for humans

- Data capturing, sensors, monitoring and control for products

- Data capturing, sensors, monitoring and control for machines/equipment

- Big data and Analytics

- Cloud computing

- Additive manufacturing 
- Horizontal/vertical digital integration software

○ Cyber Security

- Artificial intelligence

- Augmented reality

- Cyber physical systems

- Virtual reality

- Collaborative robots

o Other:

6. What are the most significant outcomes of your investigation(s) on I4.0 technologies? *

7. Approximately, how much (Euros) have you and your research group invested in I4.0 laboratories in the last 2 years? *

Section 3

NEW CHALLENGES IN I4.0 AND FUTURE PERSPECTIVES

8. Which of the following technologies/principles do you consider to be the most closest to I4.0? ${ }^{*}$

- Reconfigurable/flexible manufacturing systems

- Computer integrated manufacturing

- ERP

- Cloud manufacturing

○ Cyber-physical systems

- Internet of things

- Manufacturing Execution Systems - MES

o Other:

9. What are the major differentiators of I4.0 from the technologies/principles stated above (in question 8)? *

Please use the following empty space:

10. In your opinion, which areas in I4.0 require urgent academic research attention? *

○ Driving and supporting implementation issues in practice

- Performance measurement and cost-benefit analysis

- Inhibitors and Enablers for I4.0

- Maturity Models for I4.0

- New mathematical models for I4.0

○ Workers training and workers re-skilling for I4.0

- I4.0 technologies impact on humans

- Human-machine interface and collaborative robots

- Resilience, risk and the Ripple effect analysis in I4.0 implementation

- Cost computation in I4.0 implementation

- Measurement of I4.0 competence

o Other:

11. In your opinion, which methodologies seem particularly appropriate for such research? *

- Case studies

- Surveys

- Experiments

- Conceptual frameworks/models

- Optimization and Simulation

- Data analytics

o Other:

12. What about the next step? Which of the following paradigms do you consider to be the most suitable to be addressed in Industry 5.0?*

- Collaborative industry: a new link between humans and technologies

- Social sustainability as major focus

- Human-machine interface and cooperation

- Interaction between Human Intelligence and Artificial Intelligence

- Re-skilling and new opportunities for human workers

- A new role of human creativity in production

- Circular Economy and Closed Loop Supply Chains

- Collaborative robotics

- Artificial Intelligence

- Supply Chain Resilience, Ripple Effect and Risk Management

o Other: 


\section{Appendix 2. Survey results}

In which industry sector do you see significant adoptions of Industry 4.0 in your country?

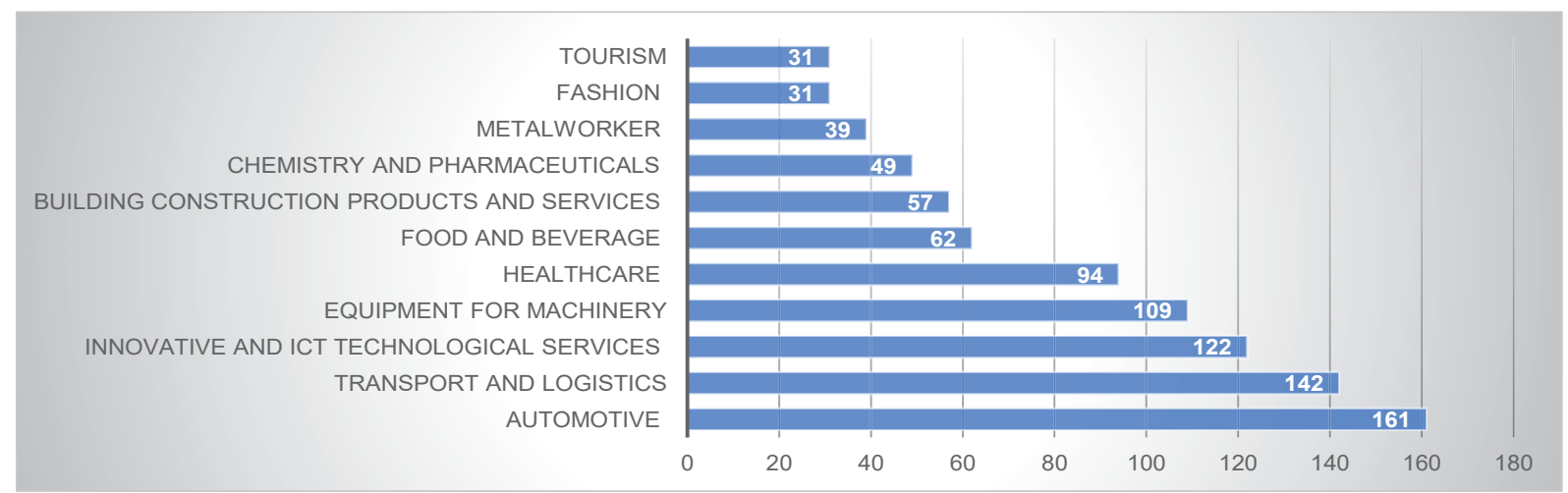

What are the significant limitations that inhibit the adoption of Industry 4.0 in your country?

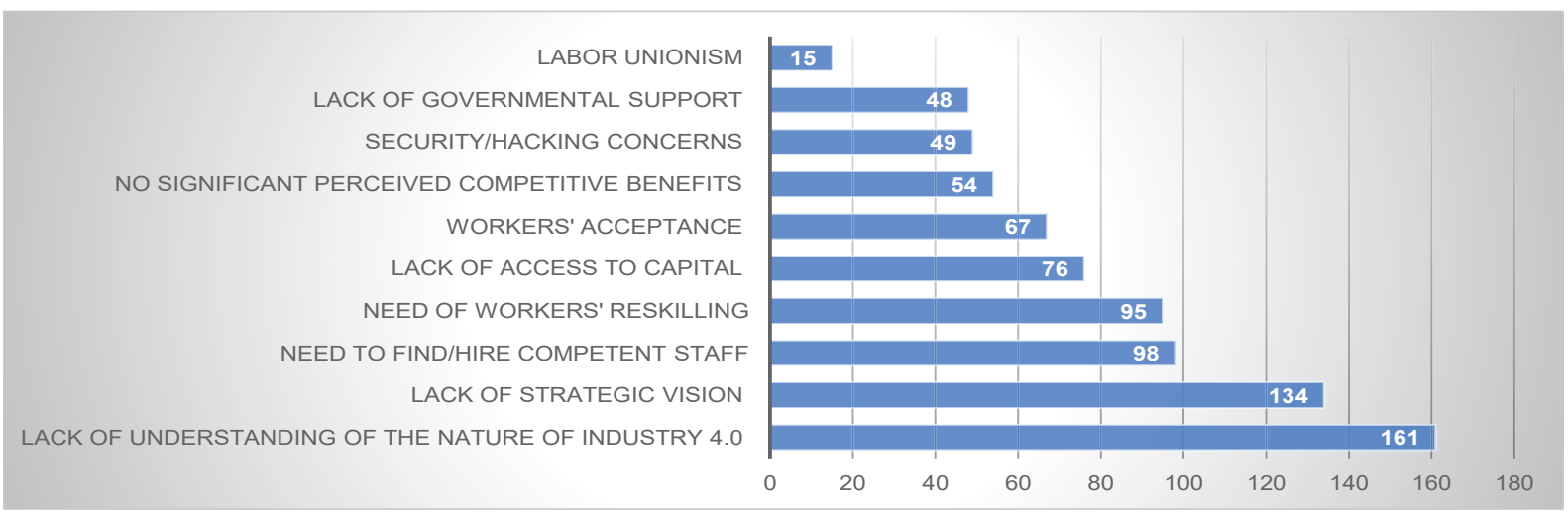

Which of the following Industry 4.0 technologies have you investigated/tested/implemented in the last 2 years?

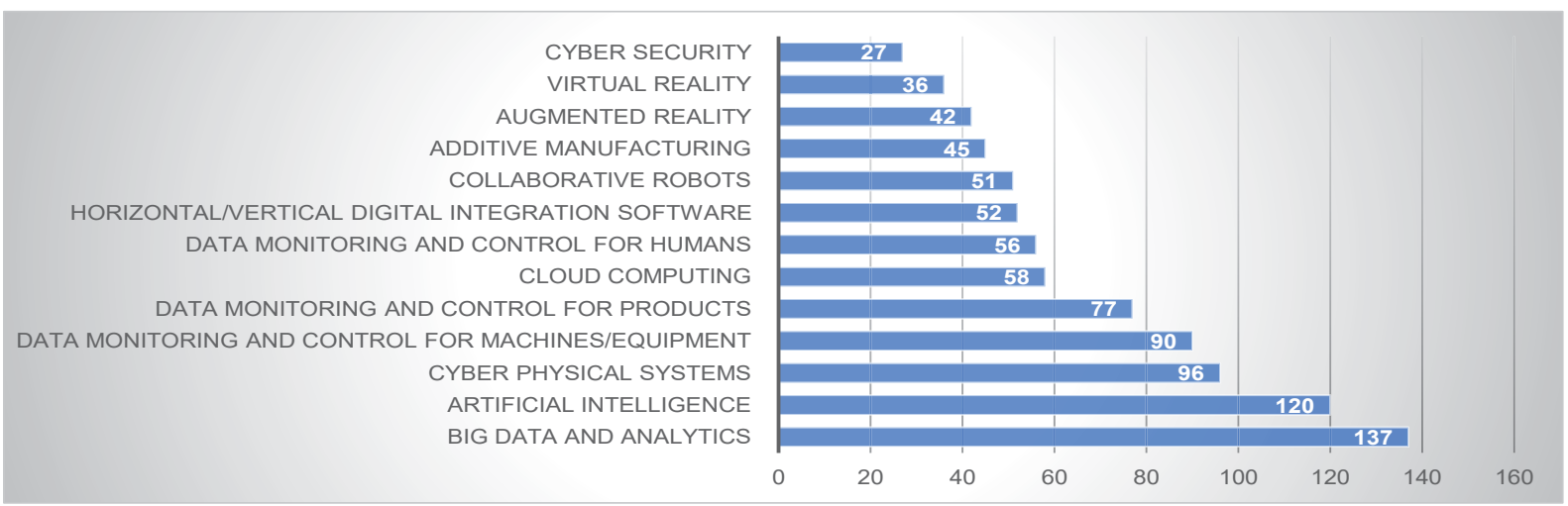

Which of the following technologies/principles do you consider to be the most closest to Industry 4.0?

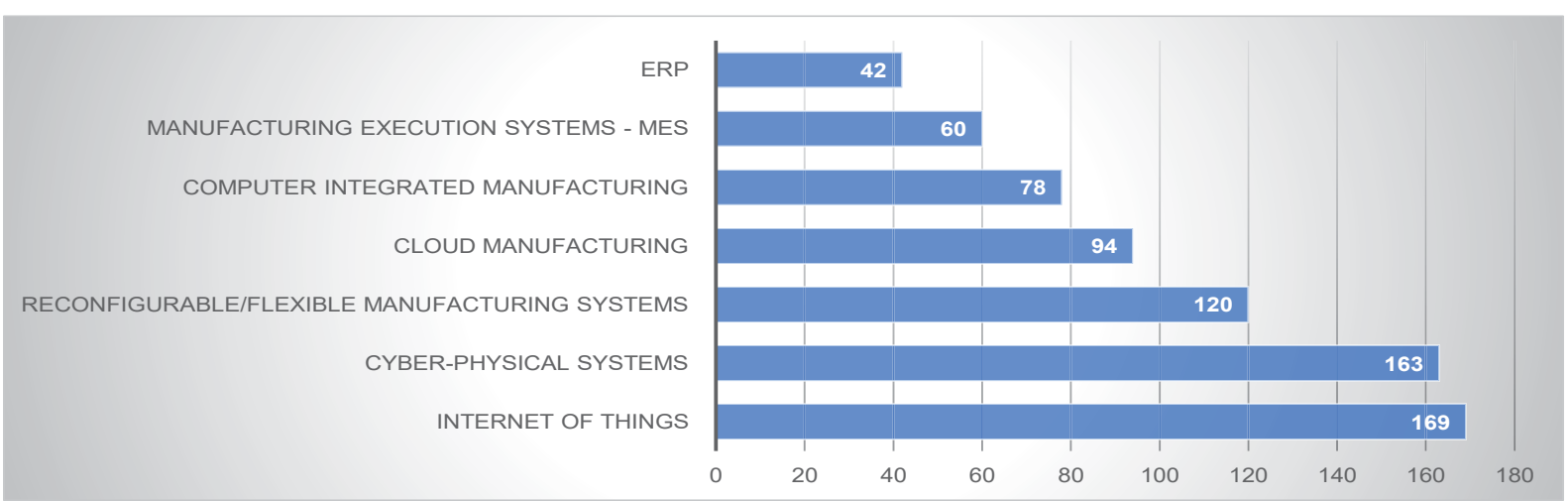


In your opinion, which areas in Industry 4.0 require urgent academic research attention?

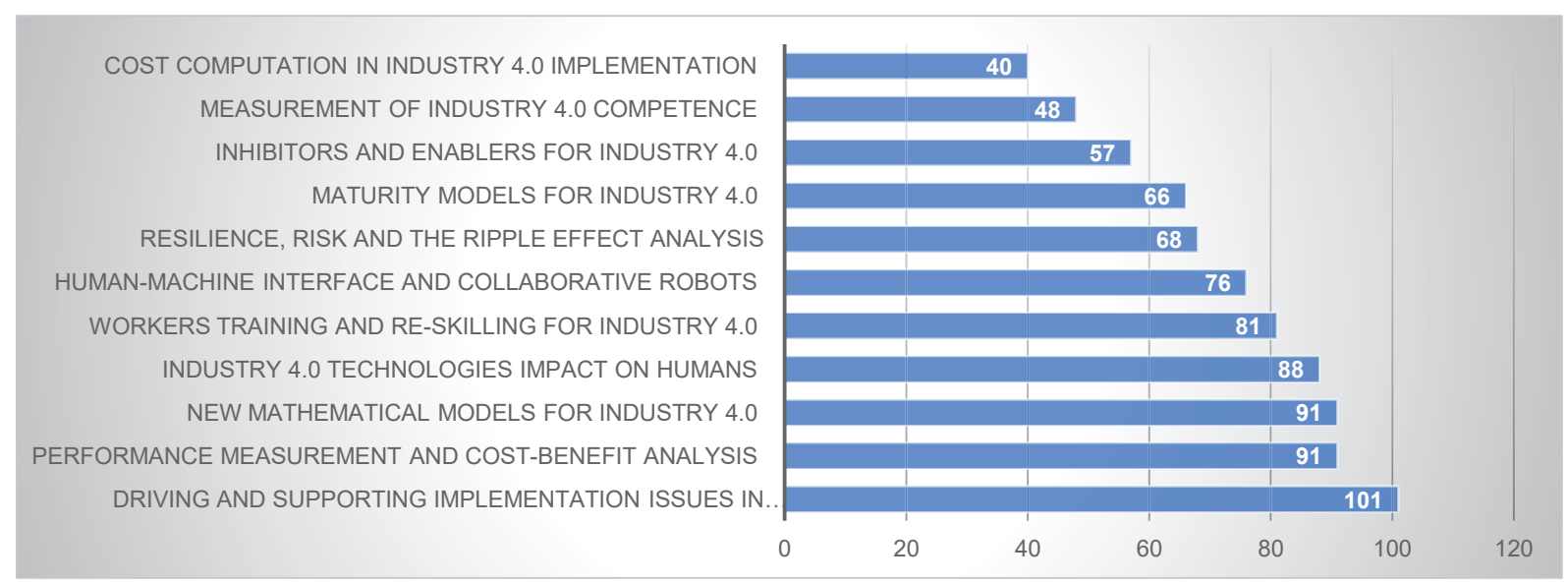

What about the next step? Which of the following paradigms do you consider to be the most suitable to be addressed in Industry 5.0?

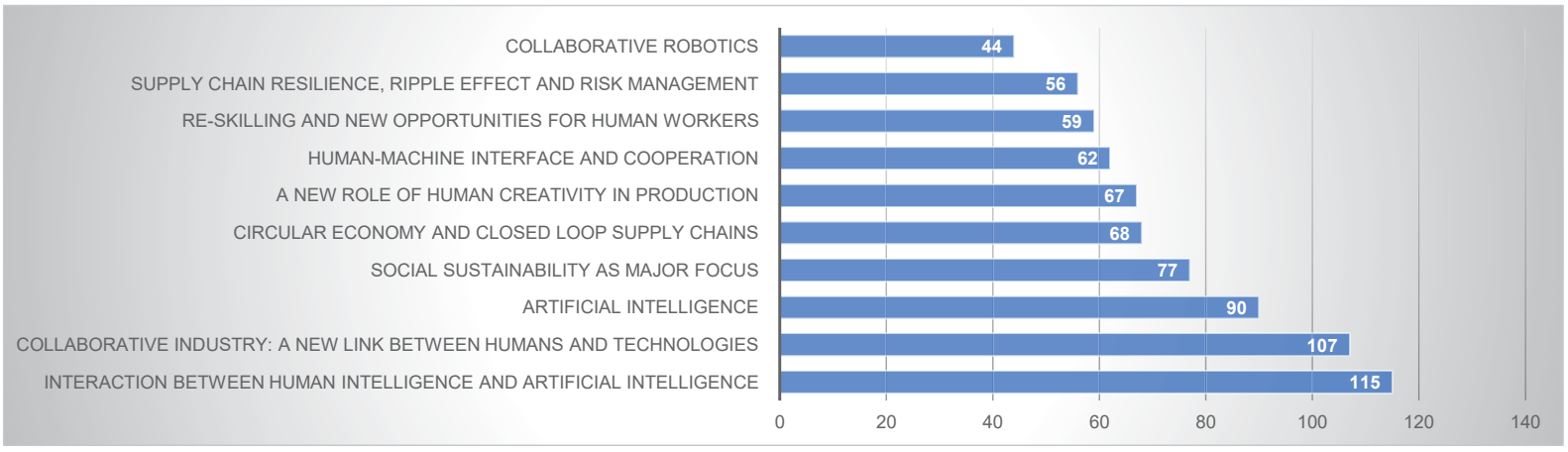

In your opinion, which methodologies seem particularly appropriate for such research?

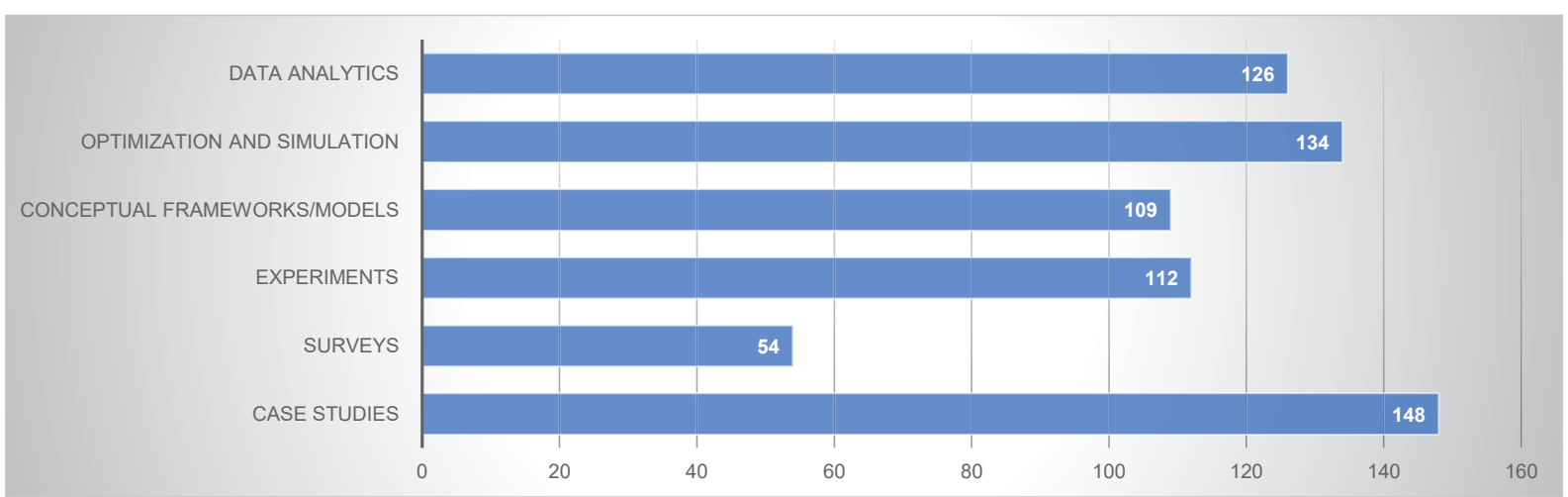


Appendix 3. Major components of I4.0 technologies

\section{Infrastructure Technology}

a) Internet-of-Things (IoT)

b) Cyber-Physical System (CPS)

2. Engineering Technology

a) Additive Manufacturing

b) Automated Guided Vehicle (AGV)

c) Collaborative Robots

d) Augmented Reality

3. Data Technology

a) Big Data Analytics (BDA)

b) Artificial Intelligence (AI)

c) Track and Trace (T\&T) systems

4. Communication Technology
a) Machine-to-Machine (M2M)
b) Cloud Services
c) Smart Products
d) Blockchain 